OPEN ACCESS

Edited by:

João Peça,

University of Coimbra, Portugal

Reviewed by:

Chan Young Shin,

Konkuk University, South Korea

Junyu Xu,

Zhejiang University, China

*Correspondence:

Emanuela Santin

emanuela.santini@ki.se

Specialty section:

This article was submitted to

Cellular Neuropathology,

a section of the journal

Frontiers in Cellular Neuroscience

Received: 30 July 2019

Accepted: 11 March 2020

Published: 31 March 2020

Citation:

Lieberman OJ, Cartocci V Pigulevskiy I, Molinari M, Carbonell J,

Broseta MB, Post MR, Sulzer D,

Borgkvist A and Santini E (2020)

mTOR Suppresses Macroautophagy

During Striatal Postnatal Development and Is Hyperactive in Mouse Models

of Autism Spectrum Disorders.

Front. Cell. Neurosci. 14:70

doi: 10.3389/fncel.2020.00070

\section{mTOR Suppresses Macroautophagy During Striatal Postnatal Development and Is Hyperactive in Mouse Models of Autism Spectrum Disorders}

\author{
Ori J. Lieberman 1,2, Veronica Cartocci ${ }^{3}$, Irena Pigulevskiy ${ }^{2}$, Maya Molinari3, \\ Josep Carbonell ${ }^{3}$, Miguel Bellés Broseta ${ }^{3}$, Michael R. Post ${ }^{1}$, David Sulzer ${ }^{1}$, \\ Anders Borgkvist ${ }^{3}$ and Emanuela Santini2,3*
}

1 Division of Molecular Therapeutics, Department of Psychiatry, Columbia University Vagelos College of Physicians and Surgeons, New York, NY, United States, ${ }^{2}$ Division of Movement Disorders, Department of Neurology, Columbia University Vagelos College of Physicians and Surgeons, New York, NY, United States, ${ }^{3}$ Department of Neuroscience, Karolinska Institute, Stockholm, Sweden

Macroautophagy (hereafter referred to as autophagy) plays a critical role in neuronal function related to development and degeneration. Here, we investigated whether autophagy is developmentally regulated in the striatum, a brain region implicated in neurodevelopmental disease. We demonstrate that autophagic flux is suppressed during striatal postnatal development, reaching adult levels around postnatal day 28 (P28). We also find that mTOR signaling, a key regulator of autophagy, increases during the same developmental period. We further show that mTOR signaling is responsible for suppressing autophagy, via regulation of Beclin-1 and VPS34 activity. Finally, we discover that autophagy is downregulated during late striatal postnatal development (P28) in mice with in utero exposure to valproic acid (VPA), an established mouse model of autism spectrum disorder (ASD). VPA-exposed mice also display deficits in striatal neurotransmission and social behavior. Correction of hyperactive mTOR signaling in VPA-exposed mice restores social behavior. These results demonstrate that neurons coopt metabolic signaling cascades to developmentally regulate autophagy and provide additional evidence that mTOR-dependent signaling pathways represent pathogenic signaling cascades in ASD mouse models that are active during specific postnatal windows.

Keywords: striatum, development, autophagy, mTOR, autism, valproic acid

\section{INTRODUCTION}

Best characterized in studies of brewer's yeast, macroautophagy (hereafter referred to as autophagy) is a degradative process for long-lived proteins and damaged organelles (Ohsumi, 2014). In neurons, autophagy is considered to play both protective and pathogenic roles, as it contributes not only to proteostasis and cell survival (Hara et al., 2006; Komatsu et al., 2006; Yamamoto et al., 2006; Yamamoto and Simonsen, 2011), but also to autophagic cell death in neurodegenerative 
diseases (González-Polo et al., 2005; Wang et al., 2006; Chakrabarti et al., 2009; Yang et al., 2011; Yamamoto and Yue, 2014). Recently, autophagy has been recognized as an important cellular process during neuronal development (Shen and Ganetzky, 2009; Tang et al., 2014; Dragich et al., 2016; Stavoe et al., 2016; Kim et al., 2017; Lieberman et al., 2019a). Autophagic dysfunction is observed in humans with neurodevelopmental disorders (Lee et al., 2013; Poultney et al., 2013; Byrne et al., 2016; Hor and Tang, 2018), and mouse models with reduced autophagy display phenotypes implicated in autism spectrum disorders (ASD) (Tang et al., 2014; Kim et al., 2017; Yan et al., 2018). Importantly, autophagic dysfunction is found in both genetic and environmental animal models of ASD, suggesting its impairment may be a general feature of ASD pathophysiology (Tang et al., 2014; Qin et al., 2016; Zhang et al., 2016, 2019; Wu et al., 2018; Yan et al., 2018). Notably, rodents prenatally exposed to valproic acid (VPA) show a reduction in brain autophagy accompanied by a series of morphological alterations and behavioral impairments consistent with the ASD symptomatology described in patients (Qin et al., 2016; Zhang et al., 2016; Wu et al., 2018; Zhang et al., 2019). Yet, little is known about the developmental regulation of neuronal autophagy and the possible implications for ASD.

Recently, the striatum, which is the main input nucleus of the basal ganglia, a brain circuit controlling action selection and reward processing, has been implicated in the pathophysiology of multiple neurodevelopmental diseases including ASD (Gerfen and Surmeier, 2011; Fuccillo, 2016). Moreover, the principal neurons of the striatum, the spiny projection neurons (SPNs), although they migrate to the striatum during the embryonic period (Song and Harlan, 1994), undergo a significant maturation during the first four postnatal weeks. SPNs receive excitatory inputs from the cortex and thalamus during the second and third postnatal weeks (Tepper et al., 1998). Dopaminergic axons innervate the striatum at birth but their ability to release neurotransmitter increases during the first 2 weeks (Voorn et al., 1988; Lieberman et al., 2018). Finally, the intrinsic excitability of SPNs matures from weeks two through four (Tepper et al., 1998; Peixoto et al., 2016). Notably, autophagy has been proposed to contribute to synaptic maturation and plasticity and dopamine release (Hernandez et al., 2012; Tang et al., 2014; Nikoletopoulou et al., 2017). Thus, establishing whether autophagy is differentially regulated during postnatal development of the striatum and determining whether this temporal regulation is impaired in ASD would provide insights into its role in neurodevelopmental disorders.

Autophagy is a tightly regulated multi-step process (Bento et al., 2016) that, in dividing cells is controlled by energy balance (i.e., nutrient status) and metabolic kinases, including the mammalian target of rapamycin (mTOR). mTOR regulates autophagy via several mechanisms (He and Klionsky, 2009), including by phosphorylating and negatively regulating Unc51-like autophagy-activating kinase 1 (ULK1) at Ser757 (Jung et al., 2009; Kim et al., 2011). This step prevents ULK1-mediated phosphorylation of Beclin-1 at Ser14, and the subsequent increase of PI3K activity of Vps34 (Russell et al., 2013). These molecular events initiate the formation of preautophagic structures that are subsequently expanded by a molecular cascade resulting in the modification of LC3, one of the mammalian homologs of the yeast Atg8 (Shpilka et al., 2011). Processing of LC3 leads to phagophore expansion and sealing and is used as a biochemical readout of autophagosome formation (Kabeya et al., 2000; Klionsky et al., 2016). The enclosed, mature autophagosome then traffics to the lysosome where the autophagic cargo and cargo adaptors, such as p62, are degraded (Tanida et al., 2005).

Whether similar signaling regulates autophagy in neurons remains controversial. It has been proposed that autophagy may act as a constitutive process for cellular homeostasis, thus circumventing the control of metabolic kinases such as mTOR (Yamamoto and Yue, 2014). The links between nutrient status and autophagy in neurons moreover remain elusive, with reports suggesting a regional and age-specific autophagic response to nutrient deprivation in neurons (Kaushik et al., 2011; Nikoletopoulou et al., 2017) and studies indicating the contrary (Mizushima et al., 2004). Moreover, direct regulation of autophagy by mTOR, independent of nutrient status, has been reported by some (Hernandez et al., 2012; Tang et al., 2014) but not others (Tsvetkov et al., 2010; Maday and Holzbaur, 2016). These contrasting results raise important questions concerning the control of autophagic activity in brain regions implicated in neurodevelopmental diseases, the molecular changes associated with pathologic conditions and the nature of signaling pathways that regulate autophagy in neurons (i.e., signaling operating during nutrient deprivation-induced autophagy in non-neuronal cells).

Using biochemical, pharmacological and histological approaches, we first demonstrate that in SPNs autophagy is dynamically downregulated during postnatal development, following the upregulation of mTOR activity. Then we employ the VPA model of ASD which has construct, face and predictive validity (Chomiak et al., 2013; Roullet et al., 2013; Nicolini and Fahnestock, 2018) to show that in the striatum of ASD model mice, autophagy is specifically reduced during a discrete developmental window (P28). At the same postnatal age, we also observe changes in excitatory synaptic transmission. Finally, we find that mice exposed to VPA in utero display a social deficit and that systemic treatment with rapamycin, an inhibitor of mTOR, normalizes it. Our results suggest that autophagy may play temporally-specific roles in brain postnatal development and that it may be one of the pathogenic signaling pathways implicated in neurodevelopmental disorders and ASD.

\section{RESULTS}

\section{Markers of Autophagic Activity Decrease During Striatal Postnatal Development}

To identify changes in autophagic activity during postnatal striatal development, we collected striata from mice at postnatal days 10, 14, 18, 28 and in adults (postnatal day 120; Tepper et al., 1998; Peixoto et al., 2016; Lieberman et al., 2018). These postnatal ages represent critical timepoints for striatal development. Briefly, synaptic dopamine release has begun and interneurons have begun to mature in the striatum at postnatal day 10 (Plotkin et al., 2005; Ferrari et al., 2012; Lieberman et al., 2018). 
By postnatal day 14, excitatory inputs from the cortex and thalamus arrive and eye opening has occurred, providing higher levels of sensory input. P18 represents the end of synaptogenesis and an age immediately before weaning. At age P28, the period of postnatal refinement has ended (Tepper et al., 1998). We compared tissue from these ages to mice in early adulthood at postnatal day 120 .

We first measured the levels of DARPP32, a classic SPN marker, and actin as a loading control across postnatal development and found no differences (Figure 1A). We then measured the level of total and processed form of the Atg8 family member, LC3B (Tanida et al., 2005; Klionsky et al., 2016). We found a significant effect of age on the levels of processed LC3B (LC3B-ii) relative to actin and unprocessed LC3B (LC3B-i) (Figures 1A-C). The level of the autophagic adapter protein, p62, whose steady-state levels are determined by its own autophagic degradation, increased over the postnatal period (Figure 1D). These data suggest that overall autophagic activity decreases during the first four postnatal weeks.

\section{LC3 + Puncta Decrease in Striatal Spiny Projection Neurons During Postnatal Development}

Western blot analysis of total striatal lysates includes proteins from all cell types present in the striatum, including neurons, glia, and vascular cells. To define the cell type in which the developmental changes in autophagy occur, we utilized a transgenic mouse ubiquitously expressing LC3 fused to both green (GFP) and red fluorescent proteins (RFPs) (Supplementary Figure S1A; tandem fluorescent-tagged LC3 or tfLC3) (Li et al., 2014). After processing, LC3 transitions from the cytosol to become membrane-bound on the autophagosome (LC3B-ii). Visualizing the distribution of fluorophore-tagged LC3 (LC3 puncta) provides a wellestablished assay for monitoring autophagic activity within a cell (Klionsky et al., 2016). Furthermore, as the fluorescence of the GFP component is quenched by the low $\mathrm{pH}$ of the lysosome, tfLC3 permits analysis of the total number of autophagosomes and autolysosomes (RFP + puncta) and non-acidified autophagosomes (GFP + RFP + puncta).

We first used 2-photon microscopy to simultaneously image GFP and RFP signals in acute brain slices tfLC3 mice at age P10 and P28 (Supplementary Figures S1B,C). At both ages, GFP fluorescence was diffuse in the cytosol and processes of striatal cells and RFP + puncta were present in the soma. The density of the striatal neuropil prevented analysis of tfLC3 + puncta in axons or dendrites (Supplementary Figures S1B,C). Because the level of GFP fluorescence was too strong in the soma to discern individual puncta, we used the number of RFP puncta as a proxy for autophagosomes, with the caveat that we were unable to determine whether these puncta were also fused with lysosomes.

To identify the number of RFP + puncta in specific cell types, we perfused mice at age P10 and P28 and co-labeled with cell-type specific markers of striatal neurons. Spiny projection neurons can be identified by immunostaining with antibodies against DARPP-32. We observed a significant decrease in RFP + puncta in DARPP32 + cells between P10 and P28 (Figures 1E-G), indicating that the reduction in autophagic activity occurs in SPNs. To determine whether autophagy is similarly regulated in other striatal cells, we quantified the number of RFP + puncta in DARPP32- cells. We did not find a significant difference in the number of RPF + puncta in DARRP32- cells between P10 and $\mathrm{P} 28(\mathrm{P} 10=15 \pm 3.14$ and $\mathrm{P} 28=22.43 \pm 4.12$; Unpaired, twotailed $t$-test, ns; $N=3$ mice/age). These results suggest that the reduction in autophagic activity we measured using biochemical assays of striatal lysates occurs specifically in SPNs.

\section{Autophagosome Biosynthesis Is Suppressed During Postnatal Development}

Changes in the level of LC3B-ii, or the number of LC3 puncta, can arise from increases in autophagosome biosynthesis or decreases in the efficiency of autophagosome maturation and lysosomal degradation. To dissect the changes in autophagy during the postnatal period, we developed an ex vivo system to test the effects of drugs that do not cross the blood-brain barrier (Figure 2A). We generated acute brain slices from P10 or P28 mice and removed non-striatal tissue. We found that neither the slice procedure nor the incubation affected the agedependent reduction in autophagy markers observed in vivo (Figures 2A,B compared to Figure 1). This confirms that the mechanisms underlying changes in autophagic markers during postnatal development can be defined using this ex vivo system.

We incubated slices from mice at age P10 and P28 with bafilomycin A1 (BafA1, $100 \mathrm{nM}$ ), a specific inhibitor of the vacuolar proton pump, or vehicle (DMSO, 0.1\%) for $3 \mathrm{~h}$, an incubation time similar to that used in cultured cells (Klionsky et al., 2016), to prevent lysosomal acidification and block autophagosome-lysosome fusion. As treatment with BafA1 prevents LC3B-ii degradation, changes in LC3B-ii levels following BafA1 treatment are interpreted as the rate of autophagosome biosynthesis. BafA1 treatment increased LC3Bii in slices from P10 mice but, had no significant effect in slices from P28 mice (Figures 2C,D). BafA1 treatment had no effect on DARPP32 levels at either age (Figure 2C). Slices from either age treated with BafAl for $1 \mathrm{~h}$ showed no change in LC3B-ii levels (data not shown). This suggests that the higher baseline level of LC3B-ii at P10 arises from increased autophagosome biosynthesis.

\section{mTOR Signaling Is Upregulated During the Postnatal Development}

mTOR signaling is a key negative regulator of autophagic activity. We therefore hypothesized that mTOR activity in the striatum increases during postnatal development and suppresses autophagy.

mTOR kinase activity can be monitored by measuring the state of phosphorylation of its downstream targets. The level of phosphorylation at serine 757 of ULK1, which is phosphorylated by mTOR and inhibits ULK1 kinase activity (Kim et al., 2011), increased during the postnatal period in the striatum (Figures $\mathbf{3 A}-\mathbf{C}$ ). We then confirmed that ULK1 

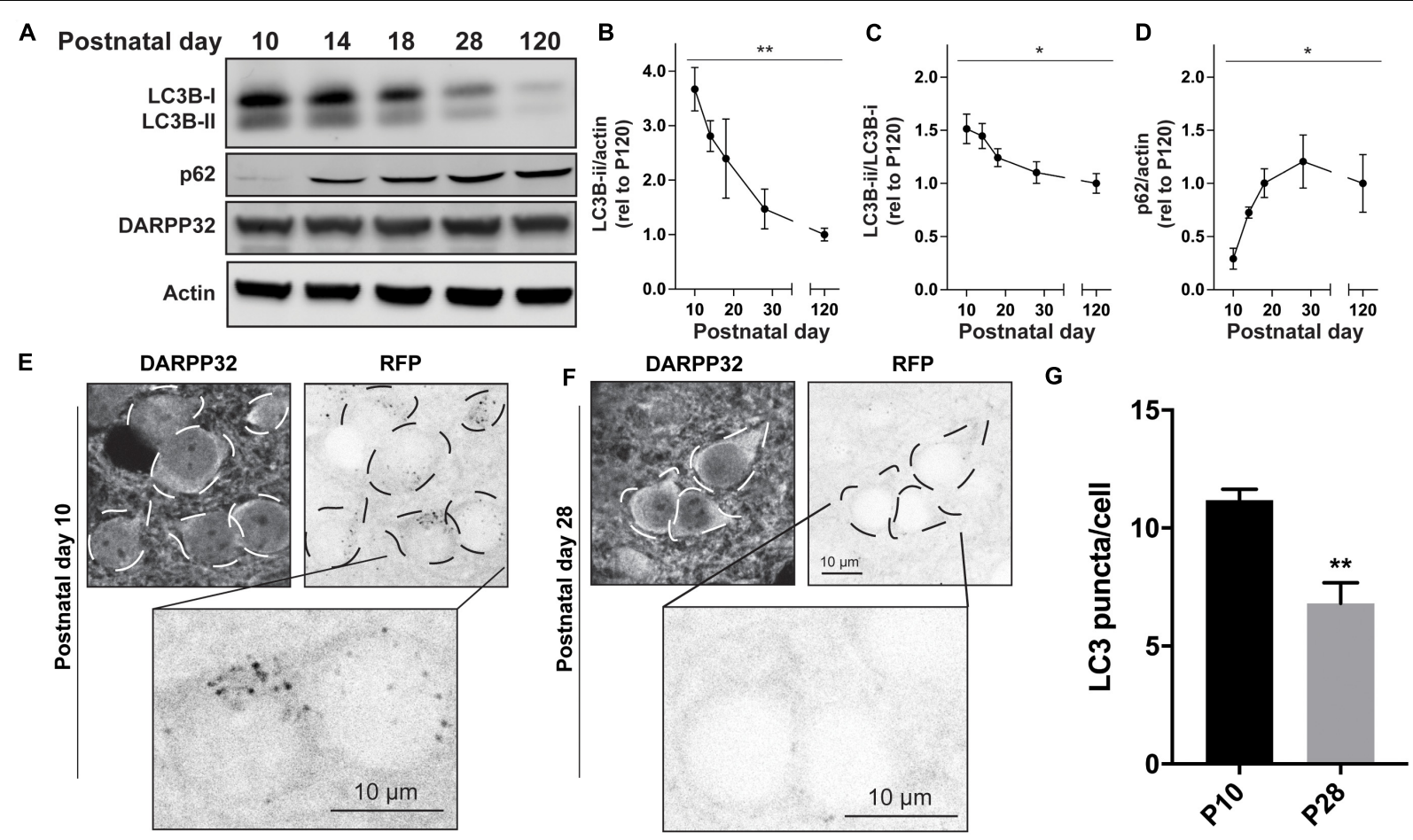

FIGURE 1 | Autophagy decreases during striatal development. (A) Representative Western blot images for LC3B, p62, DARPP32, and actin. Quantification of (B) LC3B-ii relative to actin, (C) LC3B-ii relative to LC3B-i, (D) p62 relative to actin normalized to P120 values. Data analyzed with one-way ANOVA; (B) Age: $F_{(4,21)}=6.526, p=0.0014$; (C) Age: $F_{(4,22)}=3.797, p=0.0171$; (D) Age: $F_{(4,15)}=3.762, p=0.0260$. ${ }^{*} p<0.05,{ }^{* *} p<0.01, n=4-6$ mice/age. (E,F) Representative images of DARPP32 stained striatal neurons and RFP fluorescence from mice aged P10 and P28. Dashed lines indicate cell body outlines. (G) Quantification of number of LC3 puncta/cell. Unpaired, two-tailed $t$-test, $t_{4}=4.392, p=0.0118 . \mathrm{N}=3$ mice/age, 20-50 cells were analyzed per mouse.

kinase activity is inhibited by monitoring the phosphorylation state of Beclin-1, a ULK1 target. Phosphorylation of Beclin-1 at serine 14 decreased during postnatal development (Figures 3AC). mTOR activity also leads to the indirect phosphorylation of the ribosomal protein S6 (rpS6) on serine 240 and serine 244, via activation of the S6 kinase 1 [S6K1; Figure 3A (Magnuson et al., 2012)]. We observed a sharp increase in rpS6 Ser240/244 at P18 before decreasing into adulthood (Figures 3B,D). Overall these data indicate an increase in mTOR activity during striatal postnatal development. Interestingly, we did not observe a significant effect of age on phosphorylation of ERK1/2 (Figures 3B,D) suggesting that increased mTOR activity during the postnatal period is not associated with a global change in molecular signaling.

\section{mTOR and vps34 Regulate LC3B-ii Levels During Striatal Postnatal Development}

mTOR negatively regulates autophagosome biosynthesis by inhibiting ULK1 activity (Jung et al., 2009; Kim et al., 2011). When ULK1 is active, it promotes autophagosome formation by phosphorylating Beclin-1, which increases the PI3K activity of its partner, Vps34 (Russell et al., 2013). To address whether elevated autophagy at P10 was a result of enhanced Vps34 activity, we incubated acute striatal slices with the Vps34 inhibitor,
SAR405 $(1 \mu \mathrm{M})$ or vehicle (DMSO, 0.1\%) for $3 \mathrm{~h}$ (Ronan et al., 2014). SAR405 significantly reduced the level of LC3Bii in slices from mice at age P10 but had no effect on slices from P28 mice (Figures 4A-C). This demonstrates that elevated autophagic activity in the striatum of early postnatal mice is Vps34-dependent. The lack of effect of SAR405 on autophagic activity at P28 indicates that reduced Vps34 activity, possibly via increased mTOR signaling (Figure 3), is responsible for the lower levels of autophagic flux at P28. As predicted SAR405 does not change the levels of phosphorylated Beclin-1 at P10 (veh: $100 \pm 9.433$ and SAR405: $103.2 \pm 6.982$; Unpaired, twotailed $t$-test, ns. $n=4$ slices $/ 3$ mice) and P28 (veh: $100 \pm 11.89$ and SAR405: $85.29 \pm 6.813$; Unpaired, two-tailed $t$-test, ns. $n=5$ slices $/ 3$ mice), indicating that there are no regulatory loops altering the activation of Beclin-1 in response to inhibition of Vsp34 activity.

Having shown that Vps34 drives elevated autophagy at P10, we explored whether enhanced mTOR activity inhibits autophagy at P28. mTOR activity can be pharmacologically inhibited by direct active site inhibitors, such as Torin-1 (Thoreen et al., 2009). We incubated striatal slices from mice at P28 with Torin-1 $(5 \mu \mathrm{M})$ or vehicle (DMSO, $0.1 \%$ ) for $3 \mathrm{~h}$ and measured LC3Bii levels. Torin-1 treatment increased LC3B-ii levels and the phosphorylation of Beclin-1 at the ULK1 site (Ser14), suggesting that mTOR inhibition activates autophagy in a ULK1/Beclin-1 dependent manner (Figures 4D-F). 
A

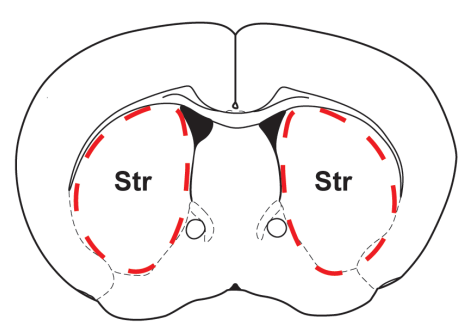

C

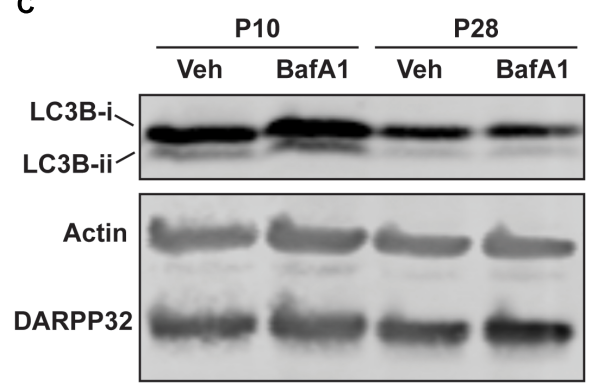

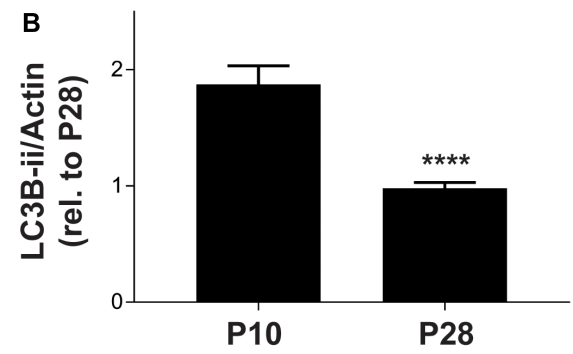

D

P10

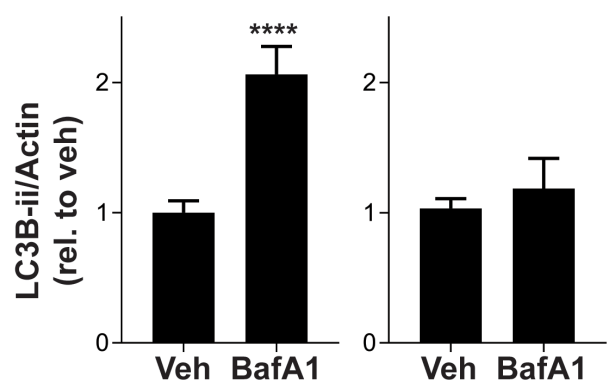

FIGURE 2 | Striatal autophagic flux decreases from P10 to P28. (A) Schematic of coronal brain section showing dissection boundaries for ex vivo experiments. (B) Quantification of LC3B-ii relative to actin for every vehicle-only slice showed in Figures 4, 5. Unpaired, two-tailed $t$-test, $t_{52}=5.824$, ${ }^{\star \star \star \star} p<0.0001$.

(C) Representative Western blot images of actin, DARPP32 and LC3B in slices obtained from P10 or P28 mice, incubated with BafA1 (100 nM, $3 \mathrm{~h}$ ) or vehicle (Veh; DMSO, 0.1\%). (D) LC3B-ii relative to actin, normalized to vehicle condition at each age. P10: unpaired, two-tailed $t$-test, $t_{25}=5.113,{ }^{* * \star *} p<0.0001$; P28: unpaired, two-tailed $t$-test, $t_{10}=0.6228, p=0.5473$. P10: Veh: $n=16$ slices, BafA1 $n=11$ slices from 4 to 6 mice. P28: Veh: $n=6$ slices, BafA1 $n=6$ slices from three mice.

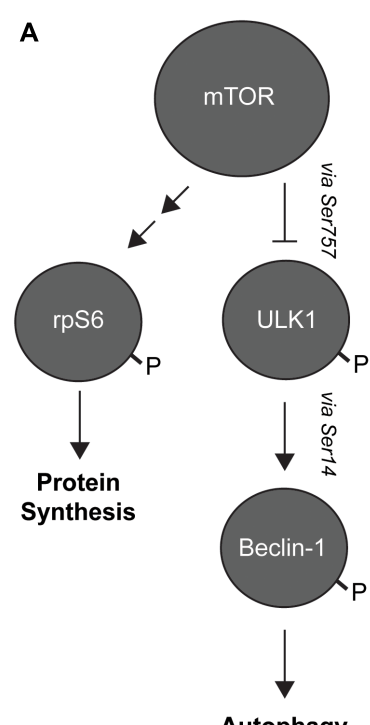

Autophagy
B

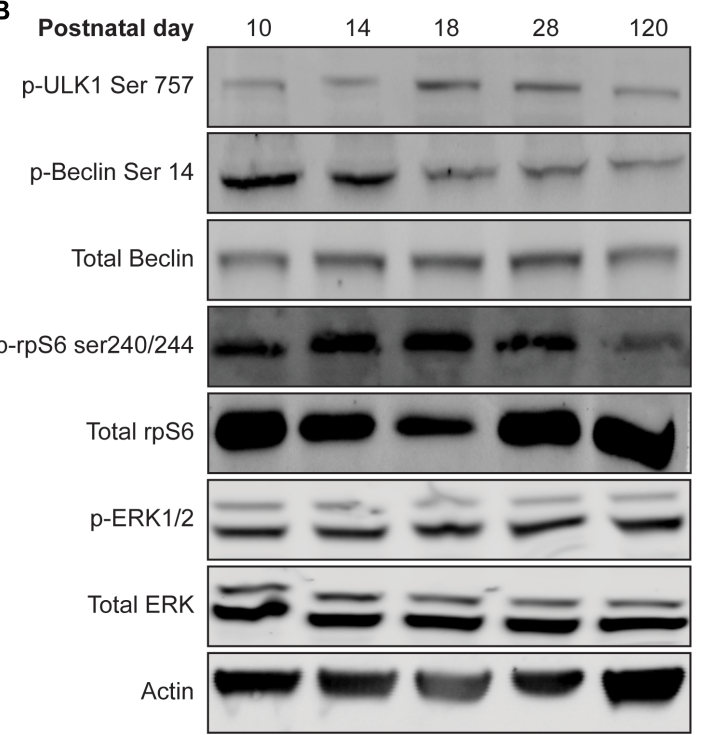

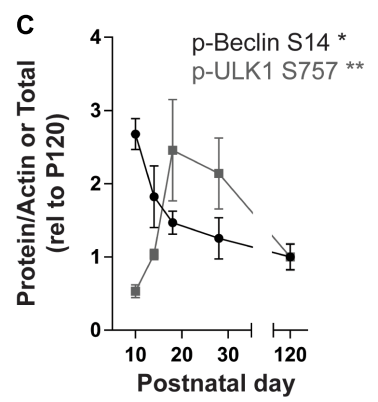

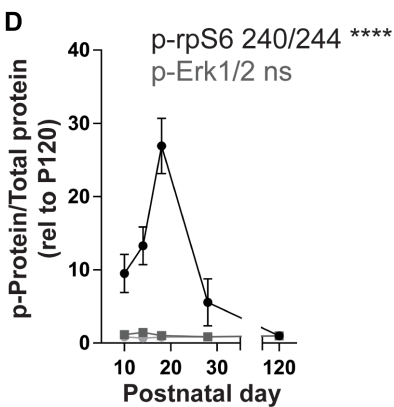

FIGURE 3 | mTOR signaling increases during striatal development. (A) Schematic representation of mTOR targets. mTOR inhibits ULK1 activity by phosphorylating Ser757. P-ULK1 activates Vps34 activity (not shown) by phosphorylating Beclin-1 on Ser14. mTOR promotes protein synthesis by activation of S6K-1 (not shown), which phosphorylates rpS6 on Ser240/244. The single and double arrows indicate direct (i.e., ULK1, Beclin-1) and indirect (i.e., rpS6) downstream targets, respectively. (B) Representative Western blot images quantified in (C,D). (C) Quantification of pULK1 S757 relative to actin (gray squares) and p-Beclin S14 relative to total Beclin-1 (black dots). Data analyzed with one-way ANOVA; p-ULK1 S757/actin: age: $F_{(4,13)}=6.093, p=0.0055 ; p-B e c l i n-1 S 14 /$ total Beclin-1: age: $F_{(4,14)}=4.945, p=0.0107$. (D) Quantification of p-rpS6 S240/244 and p-Erk1/2 relative to total rpS6 and total Erk1/2, respectively. Data analyzed with one-way ANOVA; p-rpS6 240/244: age: $F_{(4,20)}=12.69, p<0.0001$. $p$-Erk1: age: $F_{(4,17)}=2.625, p=0.0712 . p$-Erk2: age: $F_{(4,17)}=0.3561, p=0.8362 . N=3-6$ mice/age. ${ }^{*} p<0.05,{ }^{* \star} p<0.01,{ }^{\star * \star *} p<0.0001$. 


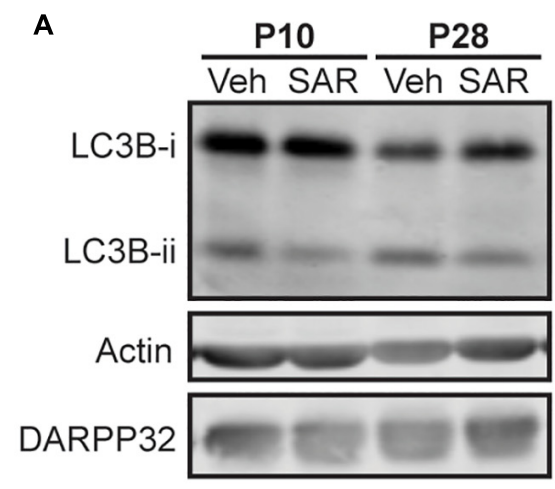

B

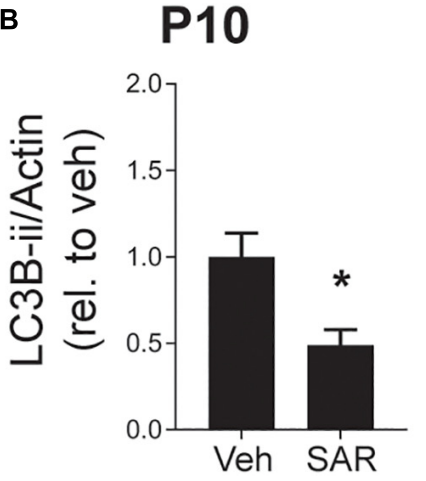

C $\quad$ P28

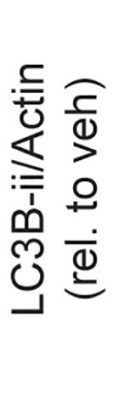

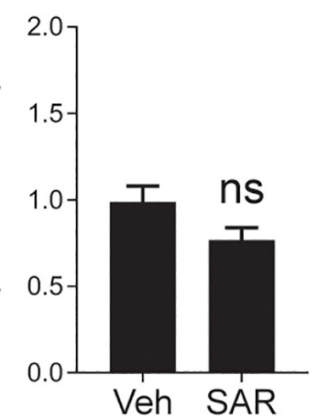

D

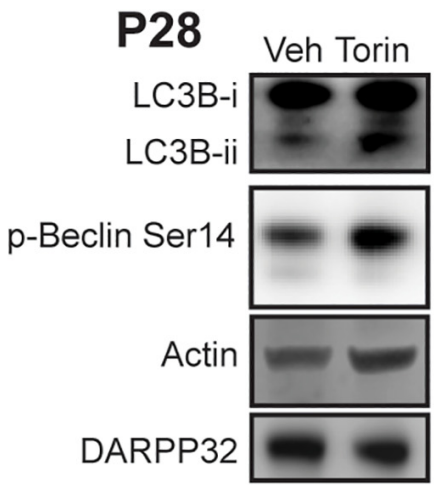

E

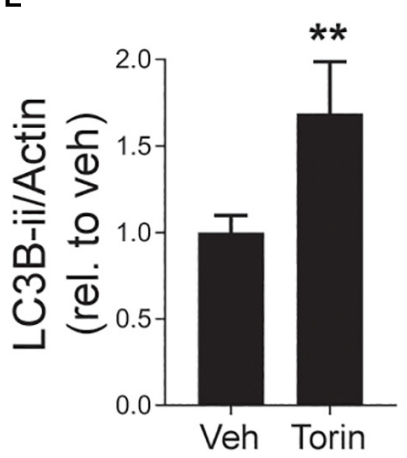

$\mathbf{F}$

FIGURE 4 | Vps34 activity is required for maintaining LC3B-ii levels at P10 and mTOR inhibition increases p-Beclin-1 and LC3B-ii levels at P28. (A) Representative Western blot images for actin, DARPP32 and LC3B-i and -ii in striatal slices obtained from P10 or P28 mice, treated with SAR405 (1 $\mu$ M) or vehicle (Veh; DMSO, $0.1 \%)$. (B,C) Quantification of LC3B-ii relative to actin, normalized to vehicle condition at each age. (B) P10: unpaired, two-tailed $t$-test, $t_{11}=2.985, p=0.0124$; P28: unpaired, two-tailed $t$-test, $t_{24}=1.807, p=0.0922$. P10: Veh: $n=6$ slices, SAR405 $n=7$ slices from 3 to 4 mice/age. (C) P28: Veh: $n=9$ slices, Baf $n=7$ slices from 3 to 4 mice/age. ${ }^{*} p<0.05$. (D) Representative Western blot images for actin, DARPP32, p-Beclin-1 Ser14 and LC3B-i and -ii in striatal slices from P28 mice, treated with Torin-1 (5 $\mu \mathrm{M})$ or vehicle (Veh; DMSO, 0.1\%). Quantification of (E) LC3B-ii and (F) p-Beclin S14 relative to actin, normalized to vehicle. Data analyzed with unpaired, two-tailed $t$-test; (E) LC3B-ii/actin, $t_{24}=2.853, p=0.0088$. Veh: $n=19$ slices, Baf $n=7$ slices from 5 to 7 mice. ${ }^{*} p<0.05$. (F) $p$-Beclin S14/actin, $t_{22}=3.337, p=0.0030 .{ }^{* \star} p<0.01$, Veh: $n=18$ slices, Torin- $n=6$ slices from 3 to 5 mice.

\section{Prenatal VPA Exposure Determine a Decrease in Autophagy During the Late Postnatal Period}

To gain insights into the involvement of autophagy in neurodevelopmental disorders and ASD, we asked whether autophagic markers are dysregulated during the postnatal striatal development in the VPA mouse model of ASD.

We examined the effects of prenatal VPA exposure $[600 \mathrm{mg} / \mathrm{kg}$ administered subcutaneously to pregnant mothers at gestational day 12 (Roullet et al., 2013)] on autophagy by collecting the striata of vehicle (Veh) or VPA-treated (VPA) mice at P10 and P28 (Figure 5A). Interestingly, we found a significant elevation in phosphorylation of rpS6 at Ser240/244 at P28 but not at P10 in VPA-treated mice compared to vehicle (Figures 5BD), suggesting that mTOR signaling was increased following in utero VPA exposure. In agreement, we observed a significant decrease in LC3B-ii and an increase of p62 at P28 but not at P10 in VPA-treated mice compared to vehicle (Figures 5B,E$\mathbf{H})$. We verified that we enriched for striatal tissue in all groups by probing for DARPP-32 (Figures 5B,I,J). Overall, these data suggest that prenatal VPA exposure affects mTOR signaling and autophagy only during the late striatal postnatal development (P28).

\section{Prenatal VPA Exposure Induces Impairments in SPNs Synaptic Transmission}

Because autophagy is important for synaptic function (Hernandez et al., 2012; Tang et al., 2014; Nikoletopoulou et al., 2017) and prenatal VPA exposure affects synaptic transmission in the hippocampus and cortex (Roullet et al., 2013), we determined whether the reduction in autophagy induced by VPA at P28 was also accompanied by a functional change in striatal synaptic transmission.

To this end we prepared acute brain slices from P28 veh- and VPA-treated mice and recorded excitatory and inhibitory synaptic transmission in SPNs. In VPA-treated mice, we discovered a decrease in the frequency and increase in the amplitude of mEPSCs compared to vehicle treated mice (Figures 6A-C). In contrast, prenatal exposure to VPA did not affect mIPSC frequency or amplitude at P28 (Figures 6D-F). This data suggest that impaired excitatory 

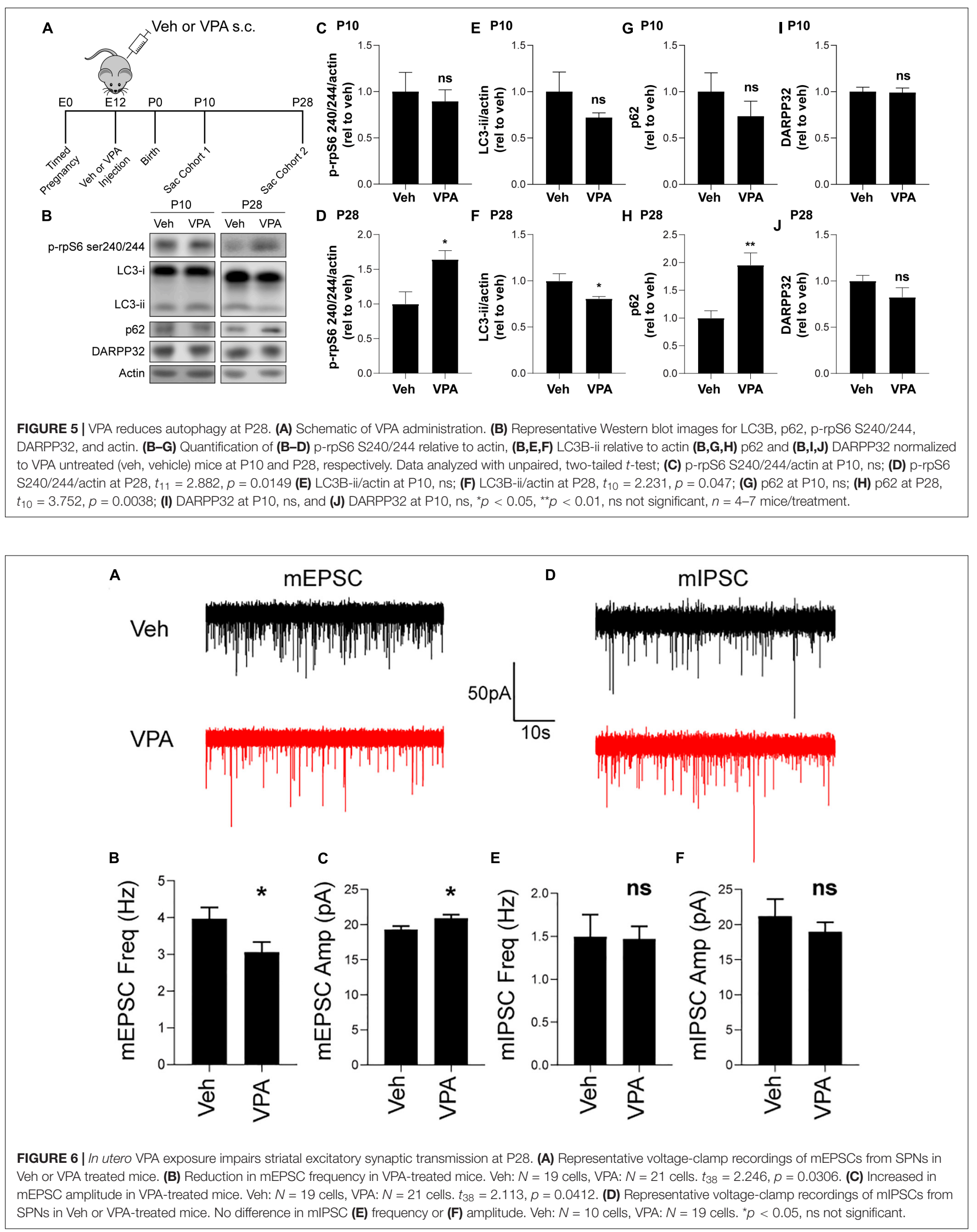
transmission occurs in SPNs of mice prenatally exposed to VPA.

\section{Prenatal VPA Exposure Induces Alteration in Social Behavior That Is Normalized by Treatment With Rapamycin}

Since repetitive behaviors and social impairments are required for ASD diagnosis [Diagnostic and Statistical Manual of Mental Disorders [DSM-5 $\left.{ }^{\circledR}\right], 2013$ ] and are present in genetic models of ASD (Kwon et al., 2006; Ehninger et al., 2008; Zhou et al., 2009; Tsai et al., 2012, 2018; Gkogkas et al., 2013; Santini et al., 2013; Huynh et al., 2015) and VPA-treated rats (Cartocci et al., 2018), we asked whether prenatal exposure to VPA could result in altered repetitive and social behaviors.

We utilized the marble burying test to determine the presence of repetitive behaviors in VPA-exposed or control mice (Thomas et al., 2009, 2012; Henderson et al., 2012; Silverman et al., 2012; Huynh et al., 2014). In this test, the mice are free to explore a cage with 20 marbles arranged in a grid on the surface of the bedding. After $20 \mathrm{~min}$ of exploration, we counted the marbles that were buried by the mice. We did not find a significant difference in the number of marbles buried by control and VPA-exposed mice (vehicle-treated mice $=12.86 \pm 1.1$, VPAtreated mice $=12.57 \pm 1.288$. Unpaired, two-tailed $t$-test, ns. $N=7$ mice/treatment). This result suggests that the onset of the repetitive behaviors occurs later than P28 for VPA-exposed mice.

We utilized the three chamber social arena to assess social behavior in VPA-exposed or control mice (Moy et al., 2008). After a period of habituation $(10 \mathrm{~min})$ to the arena, the mice are free to interact for another $10 \mathrm{~min}$ with another conspecific mouse (stranger) or with an object confined inside wire cups in the right and left chambers of the arena (Figure 7A). We found that VPA exposed mice spent significantly less time interacting with the social cue as compared to vehicle exposed mice (Figure 7B).

Since we found that VPA-exposed mice displayed an impairment in social behavior, We also investigated whether inhibiting mTOR activity with rapamycin would result in a normalization of the social abnormalities as described in genetic models of ASD (Zhou et al., 2009; Tsai et al., 2012, 2018; Tang et al., 2014). Rapamycin crosses the blood brain barrier, it has been extensively used in vivo to inhibit the activity of mTOR in the multiprotein complex 1 (mTORC1) and, rescue ASD-like behaviors (Zhou et al., 2009; Tsai et al., 2012, 2018; Tang et al., 2014). We treated VPA-exposed and control mice with rapamycin ( $5 \mathrm{mg} / \mathrm{kg}$; injected intraperitoneally (i.p.) once a day) for 4 days, a treatment that was previously showed to be effective in blocking mTOR in the brain (Ehninger et al., 2008; Santini et al., 2009; Huynh et al., 2014). On the fifth day, $1 \mathrm{~h}$ after the rapamycin injection, we subjected the mice to the three chamber arena test. Rapamycin normalized the behavior of VPA-exposed mice. Thus, after rapamycin treatment, the interaction time displayed by vehicle and VPA-treated mice is similar (Figure 7C).

Finally, one possible explanation for the social behavior displayed by VPA-exposed mice (at baseline and following rapamycin treatment) is a change in total locomotor activity.
We quantified the total locomotor activity of the mice in the three chamber arena and we found no difference between groups (Figures 7D,E), suggesting that the changes in the interaction time with the social cue are not caused by alteration in exploratory behavior.

\section{DISCUSSION}

Neuronal autophagy has been proposed to play a key role in neurodevelopment and autophagic dysfunction may lead to neurodevelopmental disorders and ASD (Tang et al., 2014; Dragich et al., 2016; Kim et al., 2017; Yan et al., 2018; Lieberman et al., 2019b). In this study we address whether autophagic activity is developmentally controlled in the principal neurons of the striatum, a brain region implicated in neurodevelopmental disorders (Fuccillo, 2016). We found that autophagy is dynamically regulated in SPNs during postnatal development, reaching adult levels around P28. These findings provide mechanistic insight into the regulation of autophagy during striatal postnatal development and establish the basis for a further evaluation of its role in physiological and pathological conditions.

The involvement of the striatum in ASD pathophysiology have been suggested by clinical and experimental observations (Fuccillo, 2016). Magnetic resonance imaging (MRI) and functional-MRI studies indicate anatomical and task-specific alterations in the striatum of ASD patients (Sears et al., 1999; Langen et al., 2007, 2009; Shafritz et al., 2008; Delmonte et al., 2012). Moreover, environmental and genetic animal models of ASD have contributed to conclusively demonstrate a causal relationship between striatal functions and pathophysiological alterations ASD-like (Arndt et al., 2005; Centonze et al., 2008; Shafritz et al., 2008; Shmelkov et al., 2010; Peça et al., 2011; Peñagarikano et al., 2011; Dölen et al., 2013; Santini et al., 2013). Interestingly, we have recently discovered that autophagy is differentially involved in the control of the synaptic functions and excitability of the two subtypes of SPNs (i.e., direct and indirect SPNs; Lieberman et al., 2020). Moreover, mice with specific genetic deletion of atg7, a protein required for autophagy, either in direct or indirect SPNs display hyperactivity, stereotypes and behavioral abnormalities consistent with ASD (Lieberman et al., 2020). Given the dynamic regulations of autophagy occurring in the SPNs during postnatal development and the ASD-like phenotypes displayed by mice with genetic ablation of autophagy in SPNs, the regulation of autophagy during early postnatal development of SPNs may be one of the cellular process disrupted in ASD.

By analyzing key endogenous biochemical markers (such as LC3B-ii, p62, p-Ser757-ULK1, and p-Ser14-Beclin-1), we discovered that autophagy decreases progressively during the postnatal development of SPNs. The autophagy markers were measured in bulk lysates containing neurons, glia and endothelial cells (among others). To identify the cell types that feature changes during postnatal development, we utilized tfLC3 mice (Li et al., 2014). Given the challenges in assaying endogenous autophagic proteins using immunofluorescence, tfLC3 mice 
A
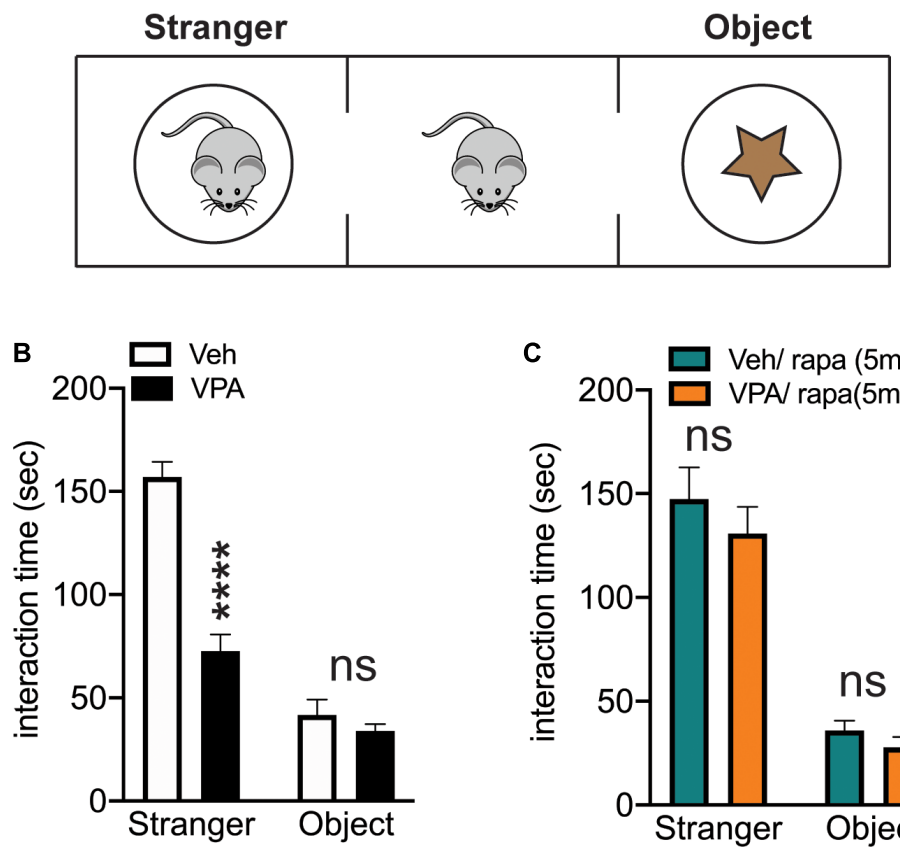

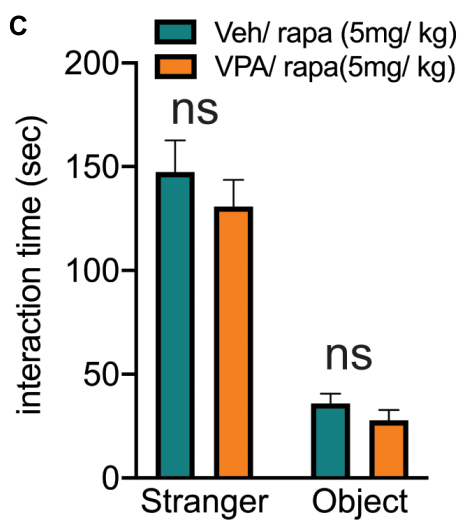

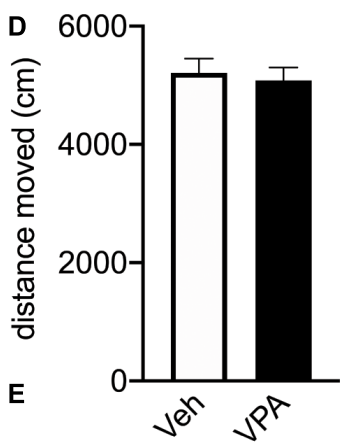

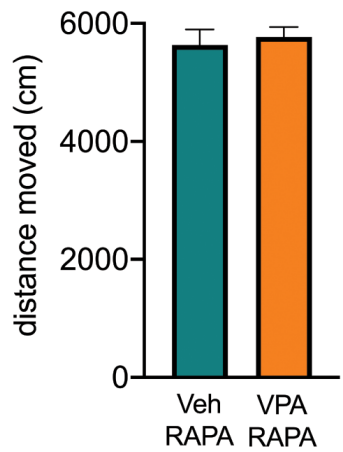

FIGURE 7 | In utero exposure to VPA reduces social approach behavior which is rescued by mTOR inhibition. (A) Schematic of three chamber arena. Subjects are placed in the center chamber and allowed to explore for 10 min. After this, a conspecific mouse (stranger) is placed in one side chamber and an object is placed in the other side chamber. The subject is allowed to explore the entire arena for 10 min and time spent interacting with either the conspecific (stranger) or the object is recorded. (B) The interaction time with stranger and object for control (Veh) and VPA-exposed mice (VPA). Two-way repeated measures ANOVA: treatment $x$ chamber $F_{(1,12)}=30.48,{ }^{* \star \star *} p<0.0001$. (C) Rapamycin treated Veh and VPA exposed mice show no difference in interaction time with the stranger. Two-way repeated measures ANOVA: treatment $x$ chamber $F_{(1,12)}=0.1397, p=0.7151$. Treatment: $F_{(1,12)}=1.584, p=0.2321$. Chamber: $F_{(1,12)}=89.93, p<0.0001$. (D,E) No difference in locomotor activity between Veh and VPA-exposed mice at baseline or following rapamycin treatment. (D) unpaired, two-tailed $t$-test, $t_{12}=0.3940, p=0.7005$. (E) Unpaired, two-tailed $t$-test, $t_{12}=0.4253, p=0.6781$.

provide a unique resource, as overexpressed LC3 is fused to fluorescent proteins that permit morphological characterization of autophagic structure. While the high levels of expression prevented the identification of individual autophagic puncta in both live imaging (Supplementary Figure S1) and fixed tissue (not shown), the level of autophagolysosomes represented by RFP-LC3 + puncta was higher in SPN somata at P10 than at P28, in agreement with our biochemical analysis (Figure 1).

Autophagic flux is determined by the kinetics of autophagosome biosynthesis, autophagosome maturation and autophagic cargo degradation by lysosomal proteases. Steady-state measurement of LC3B-ii levels provide a useful proxy for the measurement of autophagic activity. An elevated level of LC3B-ii could indicate either increased or decreased autophagic flux, as both increased autophagosome biosynthesis and decreased lysosomal degradation of autophagic proteins can increase LC3B-ii (Kabeya et al., 2000; Klionsky et al., 2016). To functionally measure autophagic flux in striatal tissue, we developed an ex vivo acute brain slice system and found that steady state increases in LC3B-ii levels at P10 were further elevated by acute blockade of lysosomal degradation with BafA1 compared to LC3B-ii levels at P28. This suggests that increased autophagic flux is responsible for the higher steady-state LC3B-ii levels, as inhibition of lysosomal degradation would not have an effect on LC3B-ii levels if lysosomal degradation were already compromised. These results indicate that the postnatal suppression of autophagy results from changes in autophagosome biosynthesis or maturation.

In line with changes in autophagosome biosynthesis/ maturation during striatal development, we found that mTORdependent signaling increases over the course of postnatal development, thereby suppressing autophagosome synthesis via inhibition of ULK1 and Beclin-1 activity. These include downstream targets involved in protein synthesis, such as rpS6, and autophagy, such as ULK1. In this regard, it is interesting to note that the phosphorylation state of rpS6 follows a slightly different pattern than ULK-1 during postnatal development. One of the reasons of this discrepancy may be the different phosphorylation kinetic of activated mTOR on the rpS6, which is an indirect target regulated via S6K-1 (Magnuson et al., 2012), and on ULK-1, which is a direct target (Kim et al., 2011). Alternatively, a reduction in phosphorylated $\mathrm{rpS} 6$ may be the result of the enhanced activity of protein phosphatase 1 (PP1), which dephosphorylates rpS6 (Belandia et al., 1994). It has been showed that the phosphorylation of rpS6 in SPNs is determined by the suppression of dephosphorylation via PKA/DARPP-32mediated inhibition of PP1 (Bonito-Oliva et al., 2013). Thus, it is possible that a reduction in PKA/DARPP-32 results in 
an increased PP1 activity which, in turn dephosphorylates rpS6. Finally, a reduction of phosphorylated rpS6 may also be achieved by increased activity of PP2A-like phosphatases, which dephosphorylate and reduce the activation of S6K-1 (Magnuson et al., 2012).

mTOR specifically phosphorylates ULK1 at Ser757 and inhibits its kinase activity (Kim et al., 2011). Consistently, we also observed a decrease in the level of phosphorylation on the ULK1 site in Beclin-1, a key component of the class III-PI3K complex required for autophagosome biosynthesis (Itakura et al., 2008; Russell et al., 2013). These results provide a functional readout for increased mTOR activity on autophagy-specific downstream targets and demonstrate a direct link between mTOR signaling and a regulation of autophagy activity observed during the postnatal development. Inhibition of mTOR activity at P28, when mTOR activity is elevated, induces autophagy and increases the phosphorylation of Beclin-1 at Ser14 and LC3B-ii levels. Further work will also focus on whether additional kinases which integrate metabolic status in the periphery, such as AMPK (He and Klionsky, 2009), control developmental changes in neuronal autophagy.

These findings may help to resolve conflicting results present in the literature. Several groups have found that mTOR inhibition fails to increase autophagic activity in primary neuronal culture (Tsvetkov et al., 2010; Maday and Holzbaur, 2016) or in vivo (Fox et al., 2010). In contrast, others report that pharmacological (Hernandez et al., 2012; Tang et al., 2014) or genetic inhibition of mTOR drives autophagy (Yan et al., 2018) as well as hyperactivation of mTOR signaling inhibits autophagy in the CNS (McMahon et al., 2012; Tang et al., 2014; Ebrahimi-Fakhari et al., 2016). This discrepancy may arise from model system used (i.e., cell culture vs. in vivo), developmental stage, or treatment paradigm. Defining the substrates that mTOR acts on during brain development is critically important given recent approvals of mTOR inhibitors in neurodevelopmental disease (French et al., 2016; Curatolo et al., 2018). Our findings suggest that mTOR signaling is important for the regulation of autophagy during critical developmental windows in neurons in a manner unrelated to nutrient status. mTOR signaling is under the control of several neural-specific signals such as patterned neuronal activity and specific neurotransmitters or neuromodulators (Yin et al., 2006; Santini et al., 2009; Auerbach et al., 2011; Bockaert and Marin, 2015; Sutton and Caron, 2015), suggesting possible mechanisms through which mTOR activity is regulated within developing neural circuits. There is a broad range of significant changes in neurotransmitter content, neuronal firing patterns and synaptic plasticity that occurs during this period, providing a plethora of candidates that could dynamically regulate mTOR signaling and autophagy during the course of postnatal development. Autophagy is also known to regulate surface levels of neurotransmitter receptors, axon pathfinding, synaptic maturation and plasticity, suggesting that autophagy acts dynamically during early postnatal developmental to entrain adult-like neuronal activity that subsequently suppresses autophagy by activating mTOR signaling (Rowland et al., 2006; Hernandez et al., 2012; Shehata et al., 2012; Tang et al., 2014; Dragich et al., 2016; Nikoletopoulou et al., 2017). Such a feedback process may provide a temporal and mechanistic framework for future studies that address the role of autophagy, and its regulation by $\mathrm{mTOR}$, in neuronal development.

The VPA animal model of ASD, a non-genetic model extensively used to study the neurobiology of ASD and to test for novel behavioral and pharmacological treatments thank to its face, construct and predictive validity (Chomiak et al., 2013; Roullet et al., 2013; Nicolini and Fahnestock, 2018). Prenatal exposure to VPA in humans is associated with neural tube defects and other congenital malformations (Jentink et al., 2010; Werler et al., 2011), neurocognitive impairments, including low IQ (Meador et al., 2013) and high risk of ASD (Bromley et al., 2013; Christensen et al., 2013). Similarly, in rodents, VPA induces a robust range of ASD-like behavioral and morphological alterations (reviewed in Chomiak et al., 2013; Roullet et al., 2013; Nicolini and Fahnestock, 2018). Adult rodents exposed to VPA display a reduction of brain autophagy in associations with the behavioral and morphological alterations (Qin et al., 2016; Zhang et al., 2016, 2019; Wu et al., 2018). In line with these results, we found altered autophagic markers, such as decreased LC3Bii and increased p62, in the striatum of P28 mice prenatally exposed to VPA. Moreover, we discover that at P10 the VPA does not significantly change autophagy. Thus, it seems that prenatal exposure to VPA determines a detectable reduction of striatal autophagy only during the late postnatal development (P28) that it is maintained in the adulthood (Qin et al., 2016; Zhang et al., 2016, 2019; Wu et al., 2018). The lack of detectable change in autophagy at P10 may be the result of the high autophagic flux that masks the impairment in autophagy. Alternatively, it may be due to an ongoing accumulation of autophagic markers that are under detectable threshold at those early time points.

Consistent with our data demonstrating a direct link between dynamic change in mTOR activity and autophagy during postnatal development of SPNs, we found an increased phosphorylation of rpS6 in VPA treated animals at P28. This result suggests that autophagy and protein synthesis are concomitantly dysregulated through aberrant mTOR activity.

Impaired protein synthesis and autophagy have also been described in genetic ASD animal models (Bagni and Zukin, 2019) and the presence of similar changes also in the non-genetic VPA model may indicate that these represent pathogenic signaling pathways underlying ASD. This molecular characterization may be of importance for early detection and therapeutic treatment of ASD.

We also discovered that reduction of autophagy in VPAtreated mice is accompanied by changes in synaptic transmission at P28. We found a decrease in frequency and increase in amplitude of mEPSCs, which may indicate a reduction in the number of spines and an increase in the strength of the synaptic connection in the striatum of mice prenatally exposed to VPA. This synaptic phenotype is in line with a previous publication reporting a reduction of corticostriatal synapses in the rostral striatum of VPA treated mice (Kuo and Liu, 2017). Moreover, decreased mEPSCs frequency in VPA treated mice is also present in the cerebellar cortex (Wang et al., 2018). Reduction in excitatory striatal inputs is also observed in genetic mouse models of ASD (Fuccillo, 2016). 
Finally, we found that mice exposed prenatally to VPA display altered social interaction in the three chamber arena test. This is similar to what is observed in rats treated with VPA (Cartocci et al., 2018). Systemic treatment with rapamycin $(5 \mathrm{mg} / \mathrm{kg} / \mathrm{day}$, injected i.p. for 5 days) normalizes the social impairments of VPA treated mice. We are aware of the fact that rapamycin will likely affect all the molecular pathways regulated by mTOR, including protein synthesis which is an important signaling cascade involved in ASD (Huynh et al., 2014). Moreover, the systemic administration of rapamycin leads to an inhibition of mTOR not only in the striatum but also in other brain regions regulating social behaviors. Further studies with more specific autophagy inhibitors administered locally or with genetic manipulation of autophagic regulators restricted to the striatum are needed to conclusively demonstrate the involvement of striatal autophagy in the generation of social deficits in the VPA animal model.

In summary, we find that the postnatal development of SPNs is correlated with a change in autophagy and this is determined by mTOR signaling status. We also find that in ASD model mice, mTOR-dependent autophagy is downregulated in SPNs and it is accompanied by impairments in synaptic transmission and social behavior in the late postnatal development.

\section{MATERIALS AND METHODS}

\section{Animals}

Breeder pairs of C57/BL6J were obtained from Jackson Laboratories (Bar Harbor, ME, United States). Mice were checked every day or every other day for pregnancy and new litters. TfLC3 mice were obtained from Jackson Laboratories [C57BL/6-Tg(CAG-RFP/EGFP/Map1lc3b)1Hill/J; Strain No. 027139]. Breeder pairs were housed on a 12-h light/dark cycle with water and food available ad libitum. Offspring were weaned between postnatal day 18 and 20 and split into same sex groups of 2-5. Mice of both sexes were utilized for experiments in Figures 1-4 and data were combined as no effect of gender was observed.

For the VPA experiments, pregnant female breeders received a single subcutaneous injection of VPA at the dose of $600 \mathrm{mg} / \mathrm{kg}$ during gestational day 12 (Lauber et al., 2016; Kuo and Liu, 2017; Wang et al., 2018). Control pregnant females received an equivalent dose of vehicle at gestational day 12. Only male mice of the offspring were utilized for these experiments (in Figures 5-7) (Lauber et al., 2016; Kuo and Liu, 2017; Wang et al., 2018).

All experimental procedures were approved by the Columbia University Institutional Animal Care and Use Committee and was conducted in accordance with animal care guidelines of National Institute of Health.

\section{In vivo Sample Preparation}

Striatal sample preparation was performed as previously described (Santini et al., 2007). Mice at specified ages were rapidly decapitated and their head was briefly placed in liquid nitrogen. The brain was subsequently removed and a single striatum was dissected and flash frozen in liquid nitrogen. Samples were stored at $-80^{\circ} \mathrm{C}$ until the full cohort was collected. Samples were then homogenized in $1 \%$ SDS by a brief sonication. Protein content was determined by the BCA assay (Thermo Fisher). No significant effect of age was found on total protein (data not shown). Samples were then boiled in sample buffer and frozen until western blot analysis.

\section{Acute Brain Slice}

Acute brain slices were prepared essentially as described (Lieberman et al., 2018). Briefly, mice underwent cervical dislocation and the brain was removed and placed in ice-cold high sucrose cutting solution (in $\mathrm{mM}$ ): $10 \mathrm{NaCl}, 2.5 \mathrm{KCl}, 25$ $\mathrm{NaHCO}_{3}, 0.5 \mathrm{CaCl}_{2}, 7 \mathrm{MgCl}_{2}, 1.25 \mathrm{NaH}_{2} \mathrm{PO}_{4}, 180$ sucrose, 10 glucose bubbled with $95 \% \mathrm{O}_{2} / 5 \% \mathrm{CO}_{2}$ to $\mathrm{pH}$ 7.4. Brains were mounted on a VT1200 vibratome (Leica Biosystems) and coronal sections $(250 \mu \mathrm{m})$ including the striatum were collected. For the biochemistry experiments, slices were then transferred to a basin contained ice-cold cutting solution and the striatum was manually dissected. Slices were moved to scintillation vials containing $7 \mathrm{~mL}$ of ACSF (in $\mathrm{mM}$ ): $125 \mathrm{NaCl}, 2.5 \mathrm{KCl}, 25$ $\mathrm{NaHCO}_{3}, 2 \mathrm{CaCl}_{2}, 1 \mathrm{MgCl}_{2}, 1.25 \mathrm{NaH}_{2} \mathrm{PO}_{4}$, and 10 glucose bubbled with $95 \% \mathrm{O}_{2} / 5 \% \mathrm{CO}_{2}$ to $\mathrm{pH} 7.4$ at $34^{\circ} \mathrm{C}$. Slices from two mice at the same age were combined in individual experiments and split into four conditions. Slices were allowed to rest for $1 \mathrm{~h}$ followed by addition of vehicle or drug. Following incubation with drug at $34^{\circ} \mathrm{C}$ for the specified time, slices were removed and flash frozen in liquid nitrogen. After slices were collected from a complete experiment (i.e., slices from 4 to 6 mice per age, at P10 and P28), slices were homogenized by sonication in 1\% SDS and prepared as described above for Western blot analysis.

\section{Patch-Clamp Electrophysiology}

Recording pipettes were fabricated from borosilicate glass microcapillaries and had resistances of 4-6 $\mathrm{M} \Omega$ when filled with internal solution (see below). Putative SPNs were visualized in corticostriatal slices with a SliceScope (Scientifica, United Kingdom) equipped with a $40 \times 0.8 \mathrm{NA}$ waterimmersion objective (LUMPlanFLN, Olympus, United States) and Dodt contrast tube optics. Data were recorded with a MultiClamp 700B amplifier (Molecular Devices, United States), low-pass filtered at $5 \mathrm{kHz}$ and digitized at $10 \mathrm{kHz}$ with a digidata $1550 \mathrm{~b}$ to a personal computer running pClamp 11 (Molecular Devices). Cell capacitance and series resistance ( $<25 \mathrm{MOhm}$ ) were left uncompensated but were monitored by applying a hyperpolarizing voltage-command $(5 \mathrm{mV})$ at regular intervals. Recordings where series resistance increased above $25 \mathrm{MOhm}$ were discarded.

Whole cell patch-clamp recordings of miniature excitatory and inhibitory synaptic currents (mEPSCs, mIPSCs, "minis") were performed at $-70 \mathrm{mV}$ holding potential, in the presence of tetrodotoxin (TTX, $0.5 \mu \mathrm{M})$ and picrotoxin (100 $\mu \mathrm{M}$, mEPSCs) or kynurenic acid ( $1 \mathrm{mM}$, mIPSCs). For mEPSCs the recording pipette contained (in $\mathrm{mM}$ ): K-gluconate, 120; $\mathrm{KCl}$, 20; EGTA, 0.1; HEPES, 10; $\mathrm{Na}_{2}$-phosphocreatine, 5; $\mathrm{Na}_{2} \mathrm{ATP}, 4$; $\mathrm{Na}_{2} \mathrm{GTP}, 0.3$, adjusted to $\mathrm{pH} 7.25$ with $\mathrm{KOH}(300 \mathrm{mOsm} / \mathrm{l})$, and for mIPSCs the pipettes contained (in $\mathrm{mM}$ ): $\mathrm{KCl}, 140$; HEPES, 10; EGTA, 1; 
$\mathrm{Na}_{2}$ ATP, 2; $\mathrm{Na}_{2} \mathrm{GTP} 0.2 ; \mathrm{pH}$ 7.25. Recordings were performed at $32-34^{\circ} \mathrm{C}$ (TC324C, Warner Instruments, United States).

The cells were filled with recording solution for at least $10 \mathrm{~min}$ and data was collected during $3 \mathrm{~min}$. The amplitude and frequency of the minis were analyzed off-line using Clampfit 10.7. Traces were filtered at $1 \mathrm{kHz}$ and synaptic events were detected using the event detection function and template search. The amplitude and frequency from each recording were averaged and group comparisons were performed between slices using unpaired $t$-test assuming equal variances. The number of mice were $>4$ per group.

\section{Western Blot}

Equivalent amount of protein per sample $(5-25 \mu \mathrm{g} /$ well $)$ were loaded into 10,12 , or $4-12 \%$ gradient polyacrylamide gels as described (Santini et al., 2007). Protein was transferred from the gel to an Immobilon FL PVDF membrane (pore size $0.2 \mu \mathrm{m}$ ). Blots were blocked in TBS with $0.1 \%$ Tween-20 (TBST) and $5 \%$ fat-free, dry milk for $1 \mathrm{~h}$ at room temperature. Blots were then incubated with primary antibody (see Table $\mathbf{1}$ for detailed information regarding antibodies) diluted in TBST with 5\% BSA as specified (see Table $\mathbf{1}$ for dilution and antibody sources) overnight at $4^{\circ} \mathrm{C}$. Blots were then washed with TBST and incubated in secondary antibody for $1 \mathrm{~h}$ at room temperature. Blots were developed using either the Odyssey imaging system (LICOR) or an enhanced chemiluminescence (ECL) system (Amersham) and imaged using an Azure Biosystems C600 system. Western blots developed using the Odyssey system were analyzed in Image Studio Lite (LICOR). Western blots developed with the ECL system were analyzed using standard routines in ImageJ. All samples were probed for beta-actin and DARPP32 as loading and dissection controls, respectively.

\section{Drugs and Chemicals}

Sodium valproate (VPA) was purchased from ACROS Organics, dissolved in saline solution and administered subcutaneously to pregnant females at the dose of $600 \mathrm{mg} / \mathrm{kg}$. BafA1 and Torin1 were purchased from Tocris. SAR 405 was purchased from Cayman Chemicals. Unless otherwise stated, all drugs were dissolved in DMSO and slices were incubated in ACSF containing the drugs or equivalent volume of vehicles for $3 \mathrm{~h}$ at $34^{\circ} \mathrm{C}$. DMSO did not exceed a final concentration of $0.1 \%$. All other chemicals were purchased from Fisher Scientific.

Bafilomycin A1 was used at a concentration of $100 \mathrm{nM}$, a concentration that effectively blocks autophagolysosome fusion in primary neuronal culture and in transformed cell lines (Yamamoto et al., 1998; Maday and Holzbaur, 2016; Redmann et al., 2017). SAR405 was used at $1 \mu \mathrm{M}$ in acute brain slice experiments. This concentration showed both maximal efficacy in inhibiting autophagy and no off target effects in cell culture experiments (Ronan et al., 2014). Torin-1 was used at $5 \mu \mathrm{M}$. Rapamycin, another mTOR inhibitor is generally used at concentrations between 1 and $5 \mu \mathrm{M}$ in both cell culture and in acute brain slice; however, Torin-1 has an IC50 of mTORC1 activity about $5 \mathrm{X}$ greater than the IC50 of rapamycin (Thoreen et al., 2009). Therefore, we used $5 \mu \mathrm{M}$ and confirmed that this inhibited rpS6 phosphorylation and mTOR activity in the acute brain slice.

Rapamycin (LC Laboratories) was dissolved in 1\% DMSO and $5 \%$ Tween- 80 in saline and injected i.p. at the dose of $5 \mathrm{mg} / \mathrm{kg}$ (vehicle treated mice received an equivalent dose of vehicle). Rapamycin $(5 \mathrm{mg} / \mathrm{kg})$ was injected i.p. once a day for 5 days. On the last day of the treatment, the mice were subjected to the three chamber sociability test (see below) $1 \mathrm{~h}$ after the injection. This regimen was chosen because it generates brain rapamycin concentrations in a range previously established to inhibit mTOR and normalize ASD-like behaviors and behaviors dependent on mTOR activation (Ehninger et al., 2008; Zhou et al., 2009; Huynh et al., 2014; Tsai et al., 2018).

\section{2p-Microscopy}

Two-photon images were acquired on a Prairie Ultima microscope system (Middleton, WI, United States) using PrairieView 4.3 software. Acute brain slices were transferred into a chamber and perfused with oxygenated ACSF at room temperature. Samples were excited with a Coherent (Santa Clara, CA, United States) Chameleon Ultra two-photon laser at $980 \mathrm{~nm}$, and images were simultaneously collected through

TABLE 1 | Antibodies.

\begin{tabular}{llll}
\hline Antibody & Company (Catalog No.) & Dilution & Detection method \\
\hline Rabbit anti LC3B & Novus Biologicals (NB600-1384) & $1: 1000$ & Odyssey \\
Rabbit anti p62 & MBL (PMO45) & $1: 1000$ & $\begin{array}{c}\text { Odyssey } \\
\text { gel required } \\
\text { Atg7KO validated } \\
\text { (data not shown) }\end{array}$ \\
Rabbit anti Darpp32 & Cell Signaling Technology (2306) & $1: 2500-5000$ & Odyssey \\
Mouse anti $\beta$-Actin & Novus Biologicals (NB600-501) & $1: 5000-10000$ & Odyssey \\
Rabbit anti p-ULK1 (Ser757) & Cell Signaling Technology (6888) & $1: 500$ & Odyssey \\
Rabbit anti Beclin & Cell Signaling Technology (3495) & $1: 1000$ & ECL \\
Rabbit anti p-Beclin-1 (Ser14) & Cell Signaling Technology (84966) & $1: 1000$ & ECL \\
Rabbit anti S6 ribosomal protein & Cell Signaling Technology (2217) & $1: 1000-2000$ & ECL \\
Rabbit anti p-S6 ribosomal protein (Ser240/244) & Cell Signaling Technology (2215) & $1: 1000-2000$ & ECL \\
Rabbit anti p44/42 MAPK (Erk1/2) & Cell Signaling Technology (4695) & $1: 1000$ & Odyssey \\
Rabbit anti p-p44/42 MAPK (Erk1/2; Thr202/Tyr204) & Cell Signaling Technology (4370) & $1: 1000$ & Odyssey
\end{tabular}


two photomultiplier tube channels with corresponding 585630 and 490-560 $\mathrm{nm}$ emission windows. The objective used was a $60 \mathrm{X}, 0.9 \mathrm{NA}$ water immersion lens, and images were $1024 \times 1024$ pixels in size.

\section{Immunohistochemistry}

Mice were deeply anesthestized and transcardially perfused with $0.9 \% \mathrm{NaCl}$ followed by $4 \%$ paraformaldehyde (PFA) in $0.1 \mathrm{M}$ phosphate buffer (PB). Brains were removed and post-fixed overnight in $4 \% \mathrm{PFA}$ in $0.1 \mathrm{M} \mathrm{PB}$. Brains were then washed three times in $1 \mathrm{X}$ phosphate buffered saline and cut into $40 \mu \mathrm{m}$ sections using a VT1200 vibratome (Leica Biosystems) and stored in cryoprotectant $(0.1 \mathrm{M} \mathrm{PB}, 30 \%$ glycerol, $30 \%$ ethylene glycol) at $-20^{\circ} \mathrm{C}$. For immunofluorescence analysis, sections were washed in TBS three times and then blocked and permeabilized for $1 \mathrm{~h}$ at room temperature with $10 \%$ normal donkey serum (Jackson Immunoresearch) and $0.1 \%$ Triton-X in TBS. Sections were then incubated overnight at $4^{\circ} \mathrm{C}$ with primary antibodies in $2 \%$ normal donkey serum, $0.1 \%$ Triton-X in TBS. Primary antibodies included: Rabbit antiDARPP32 (Cell Signaling), and Chicken anti-Green Fluorescent Protein (Abcam). Secondary antibodies with the appropriate conjugated fluorphores were purchased from Invitrogen. The endogenous fluorescence of RFP was imaged. Sections were then washed in TBS and mounted. Images were obtained using a Leica SP5 confocal system with argon, DPSS $\mathrm{He} / \mathrm{Ne}$ lasers. Images were obtained with a $63 \mathrm{X}$ oil immersion objective with a $2 \mathrm{X}$ digital zoom at $2048 \times 2048$ resolution $(\sim 120 \mathrm{~nm}$ resolution). All images were taken with the same laser intensity and detector settings with non-saturating pixel intensities.

Image analysis was conducted in ImageJ. Cell bodies were segmented using DARPP32 stained (DARPP32+) and not stained (DARPP32-) cells. RFP + puncta within each segment was counted manually. 10-20 cells were counted per section, 2-4 sections were counted per animal. Average number of puncta per cell was determined from $n=3$ animals per age. All images were collected, and all analyses were conducted blind to condition.

\section{Marble Burying Test}

Marble burying was measured as previously described (Arndt et al., 2005; Centonze et al., 2008; Shafritz et al., 2008; Shmelkov et al., 2010; Peça et al., 2011; Peñagarikano et al., 2011; Dölen et al., 2013; Santini et al., 2013). Briefly, 20 glass marbles (around $15 \mathrm{~mm}$ in diameter) were arranged in a symmetrical $(4 \times 5)$ grid on the surface of $2-3 \mathrm{~cm}$ deep bedding in clean, standard mouse cages with transparent wall extensions $(20 \mathrm{~cm})$ to avoid climbing or jumping of mice. Each mouse was placed in the center of the cage for a 20-min exploration period, after which the number of marbles buried was tallied by investigators blind to the treatment. 'Buried' was defined as $>50 \%$ covered by bedding according to Thomas et al. (2009). Testing was performed under dim light $(\sim 15$ lux $)$ and recorded with a videocamera.

\section{Three Chamber Sociability Test}

Social behavior was measured using a 3-chambered social arena as described previously (Moy et al., 2008). Briefly, mice received a 10 min habituation session to the arena in the presence of two wire cages, one in each side of the chamber. A $10 \mathrm{~min}$ social preference test followed in which the mice were allowed to explore the arena containing a wired cage with a conspecific mouse (stranger mouse) or a wire cage with an inanimate object in the two lateral chambers. The placement of social and non-social targets was counterbalanced between animals. The measured parameters of social interaction and locomotor activity were the interaction time (sec) with each target (during the social preference test session) and the total distance $(\mathrm{cm})$ moved (during habituation and social preference test sessions) respectively, calculated by Ethovision XT video tracking software (Noldus).

\section{Statistical Analysis}

All analysis was conducted blind to condition. For statistical analysis between two groups, unpaired, two-tailed $t$-tests were used. For analysis between three or more groups, one-way ANOVA was used. Sociability test was analyzed with two-way repeated measure ANOVA (within factors: treatment and social cue), followed by multiple comparisons using Bonferroni's test. Normality was not formally tested. Sample size was not based on a formal power analysis but was based on past work from our groups and similar experiments from the literature. Statistical analysis was conducted in GraphPad Prism 7 (La Jolla, CA, United States). All bar graphs show the mean \pm SEM.

\section{DATA AVAILABILITY STATEMENT}

The datasets generated for this study are available on request to the corresponding author.

\section{ETHICS STATEMENT}

The animal study was reviewed and approved by Columbia University Institutional Animal Care and Use Committee.

\section{AUTHOR CONTRIBUTIONS}

OL and ES: conception. OL, MP, AB, and ES: methodology. OL, IP, VC, MM, MB, MP, JC, AB, and ES: investigation. OL: writing - original draft and visualization. OL, IP, MP, DS, AB, and ES: writing - review and editing. ES: supervision. DS and ES: funding acquisition.

\section{FUNDING}

OL was supported by NIH T32 GM007367 and NIH F30 MH114390, VC by The Foundation Blanceflor Boncompagni Ludovisi, née Bildt, MP by NIH 5T32MH020004, DS by NIH R01 DA007418 and the Simons and JPB Foundations, AB by Swedish Research Council (2016-03129), Magnus Bergvall Foundation, Åhlens Stiftelse, The Karolinska Institute Strategic Research Program in Neuroscience (StratNeuro) and ES by NIH R00 
NS087112, Swedish Research Council (2016-02758), The Knut and Alice Wallenberg Academy Fellowship, The Olle Engkvist Byggmästare Foundation, The Karolinska Institute StratNeuro and The Karolinska Institute Internal Fund.

\section{ACKNOWLEDGMENTS}

We thank Ai Yamamoto for insightful discussions about the manuscript; Dritan Agalliu for generously sharing the LICOR

\section{REFERENCES}

Arndt, T. L., Stodgell, C. J., and Rodier, P. M. (2005). The teratology of autism. Int. J. Dev. Neurosci. 23, 189-199. doi: 10.1016/j.ijdevneu.2004.11.001

Auerbach, B. D., Osterweil, E. K., and Bear, M. F. (2011). Mutations causing syndromic autism define an axis of synaptic pathophysiology. Nature 480, 63-68. doi: 10.1038/nature10658

Bagni, C., and Zukin, R. S. (2019). A synaptic perspective of fragile X syndrome and autism spectrum disorders. Neuron 101, 1070-1088. doi: 10.1016/j.neuron. 2019.02.041

Belandia, B., Brautigan, D., and Martín-Pérez, J. (1994). Attenuation of ribosomal protein $\mathrm{S} 6$ phosphatase activity in chicken embryo fibroblasts transformed by Rous sarcoma virus. Mol. Cell. Biol. 14, 200-206. doi: 10.1128/mcb.14.1.200

Bento, C. F., Renna, M., Ghislat, G., Puri, C., Ashkenazi, A., Vicinanza, M., et al. (2016). Mammalian autophagy: how does it work? Annu. Rev. Biochem. 85, 685-713. doi: 10.1146/annurev-biochem-060815-14556

Bockaert, J., and Marin, P. (2015). mTOR in brain physiology and pathologies. Physiol. Rev. 95, 1157-1187. doi: 10.1152/physrev.00038.2014

Bonito-Oliva, A., Pallottino, S., Bertran-Gonzalez, J., Girault, J.-A., Valjent, E., and Fisone, G. (2013). Haloperidol promotes mTORC1-dependent phosphorylation of ribosomal protein S6 via dopamine- and cAMP-regulated phosphoprotein of $32 \mathrm{kDa}$ and inhibition of protein phosphatase-1. Neuropharmacology 72, 197-203. doi: 10.1016/j.neuropharm.2013.04.043

Bromley, R. L., Mawer, G. E., Briggs, M., Cheyne, C., Clayton-Smith, J., GarcíaFiñana, M., et al. (2013). The prevalence of neurodevelopmental disorders in children prenatally exposed to antiepileptic drugs. J. Neurol. Neurosurg. Psychiatry 84, 637-643. doi: 10.1136/jnnp-2012-304270

Byrne, S., Jansen, L., U-King-Im, J.-M., Siddiqui, A., Lidov, H. G. W., Bodi, I., et al. (2016). EPG5-related Vici syndrome: a paradigm of neurodevelopmental disorders with defective autophagy. Brain 139, 765-781. doi: 10.1093/brain/ awv393

Cartocci, V., Catallo, M., Tempestilli, M., Segatto, M., Pfrieger, F. W., Bronzuoli, M. R., et al. (2018). Altered brain cholesterol/isoprenoid metabolism in a rat model of autism spectrum disorders. Neuroscience 372, 27-37. doi: 10.1016/j. neuroscience.2017.12.053

Centonze, D., Rossi, S., Mercaldo, V., Napoli, I., Ciotti, M. T., De Chiara, V., et al. (2008). Abnormal striatal GABA transmission in the mouse model for the fragile X syndrome. Biol. Psychiatry 63, 963-973. doi: 10.1016/j.biopsych.2007. 09.008

Chakrabarti, L., Eng, J., Ivanov, N., Garden, G. A., and La Spada, A. R. (2009). Autophagy activation and enhanced mitophagy characterize the Purkinje cells of pcd mice prior to neuronal death. Mol. Brain 2:24. doi: 10.1186/1756-66062-24

Chomiak, T., Turner, N., and Hu, B. (2013). What we have learned about autism spectrum disorder from valproic acid. Patholog. Res. Int. 2013:712758. doi: $10.1155 / 2013 / 712758$

Christensen, J., Grønborg, T. K., Sørensen, M. J., Schendel, D., Parner, E. T., Pedersen, L. H., et al. (2013). Prenatal valproate exposure and risk of autism spectrum disorders and childhood autism. JAMA 309, 1696-1703. doi: 10.1001/ jama.2013.2270

Curatolo, P., Franz, D. N., Lawson, J. A., Yapici, Z., Ikeda, H., Polster, T., et al. (2018). Adjunctive everolimus for children and adolescents with treatmentrefractory seizures associated with tuberous sclerosis complex: post-hoc analysis
Odyssey system; and Gilberto Fisone for critical reading of the manuscript. This manuscript has been released as a PrePrint at bioRxiv.

\section{SUPPLEMENTARY MATERIAL}

The Supplementary Material for this article can be found online at: https://www.frontiersin.org/articles/10.3389/fncel. 2020.00070/full\#supplementary-material

of the phase 3 EXIST-3 trial. Lancet Child Adolesc. Health 2, 495-504. doi: 10.1016/S2352-4642(18)30099-30093

Delmonte, S., Balsters, J. H., McGrath, J., Fitzgerald, J., Brennan, S., Fagan, A. J., et al. (2012). Social and monetary reward processing in autism spectrum disorders. Mol. Autism 3:7. doi: 10.1186/2040-2392-3-7

Diagnostic and Statistical Manual of Mental Disorders DSM-5 ${ }^{\circledR}$ (2013). Available online at: https://www.appi.org/Diagnostic_and_Statistical_Manual_ of_Mental_Disorders_DSM-5_Fifth_Edition (Accessed July 25, 2019).

Dölen, G., Darvishzadeh, A., Huang, K. W., and Malenka, R. C. (2013). Social reward requires coordinated activity of nucleus accumbens oxytocin and serotonin. Nature 501, 179-184. doi: 10.1038/nature12518

Dragich, J. M., Kuwajima, T., Hirose-Ikeda, M., Yoon, M. S., Eenjes, E., Bosco, J. R., et al. (2016). Autophagy linked FYVE (Alfy/WDFY3) is required for establishing neuronal connectivity in the mammalian brain. eLife 5:e14810. doi: 10.7554/eLife.14810

Ebrahimi-Fakhari, D., Saffari, A., Wahlster, L., Di Nardo, A., Turner, D., Lewis, T. L., et al. (2016). Impaired mitochondrial dynamics and mitophagy in neuronal models of tuberous sclerosis complex. Cell Rep. 17, 1053-1070. doi: 10.1016/j.celrep.2016.09.054

Ehninger, D., Han, S., Shilyansky, C., Zhou, Y., Li, W., Kwiatkowski, D. J., et al. (2008). Reversal of learning deficits in a Tsc $2 \pm$ mouse model of tuberous sclerosis. Nat. Med. 14, 843-848. doi: 10.1038/nm1788

Ferrari, D. C., Mdzomba, B. J., Dehorter, N., Lopez, C., Michel, F. J., Libersat, F., et al. (2012). Midbrain dopaminergic neurons generate calcium and sodium currents and release dopamine in the striatum of pups. Front. Cell Neurosci. 6:7. doi: $10.3389 /$ fncel.2012.00007

Fox, J. H., Connor, T., Chopra, V., Dorsey, K., Kama, J. A., Bleckmann, D., et al. (2010). The mTOR kinase inhibitor Everolimus decreases S6 kinase phosphorylation but fails to reduce mutant huntingtin levels in brain and is not neuroprotective in the R6/2 mouse model of Huntington's disease. Mol. Neurodegener. 5:26. doi: 10.1186/1750-1326-5-26

French, J. A., Lawson, J. A., Yapici, Z., Ikeda, H., Polster, T., Nabbout, R., et al. (2016). Adjunctive everolimus therapy for treatment-resistant focal-onset seizures associated with tuberous sclerosis (EXIST-3): a phase 3, randomised, double-blind, placebo-controlled study. Lancet 388, 2153-2163. doi: 10.1016/ S0140-6736(16)31419-31412

Fuccillo, M. V. (2016). Striatal circuits as a common node for autism pathophysiology. Front. Neurosci. 10:27. doi: 10.3389/fnins.2016.00027

Gerfen, C. R., and Surmeier, D. J. (2011). Modulation of striatal projection systems by dopamine. Annu. Rev. Neurosci. 34, 441-466. doi: 10.1146/annurev-neuro061010-113641

Gkogkas, C. G., Khoutorsky, A., Ran, I., Rampakakis, E., Nevarko, T., Weatherill, D. B., et al. (2013). Autism-related deficits via dysregulated eIF4Edependent translational control. Nature 493, 371-377. doi: 10.1038/nature1 1628

González-Polo, R.-A., Boya, P., Pauleau, A.-L., Jalil, A., Larochette, N., Souquère, S., et al. (2005). The apoptosis/autophagy paradox: autophagic vacuolization before apoptotic death. J. Cell Sci. 118, 3091-3102. doi: 10.1242/jcs. 02447

Hara, T., Nakamura, K., Matsui, M., Yamamoto, A., Nakahara, Y., SuzukiMigishima, R., et al. (2006). Suppression of basal autophagy in neural cells causes neurodegenerative disease in mice. Nature 441, 885-889. doi: 10.1038/ nature04724 
He, C., and Klionsky, D. J. (2009). Regulation mechanisms and signaling pathways of autophagy. Annu. Rev. Genet. 43, 67-93. doi: 10.1146/annurev-genet102808-114910

Henderson, C., Wijetunge, L., Kinoshita, M. N., Shumway, M., Hammond, R. S., Postma, F. R., et al. (2012). Reversal of disease-related pathologies in the fragile $\mathrm{X}$ mouse model by selective activation of GABAB receptors with arbaclofen. Sci. Transl. Med. 4:152ra128. doi: 10.1126/scitranslmed.3004218

Hernandez, D., Torres, C. A., Setlik, W., Cebrián, C., Mosharov, E. V., Tang, G., et al. (2012). Regulation of presynaptic neurotransmission by macroautophagy. Neuron 74, 277-284. doi: 10.1016/j.neuron.2012.02.020

Hor, C. H. H., and Tang, B. L. (2018). Beta-propeller protein-associated neurodegeneration (BPAN) as a genetically simple model of multifaceted neuropathology resulting from defects in autophagy. Rev. Neurosci. 30, 261277. doi: 10.1515/revneuro-2018-2045

Huynh, T. N., Santini, E., and Klann, E. (2014). Requirement of Mammalian target of rapamycin complex 1 downstream effectors in cued fear memory reconsolidation and its persistence. J. Neurosci. 34, 9034-9039. doi: 10.1523/ JNEUROSCI.0878-14.2014

Huynh, T. N., Shah, M., Koo, S. Y., Faraud, K. S., Santini, E., and Klann, E. (2015). eIF4E/Fmr1 double mutant mice display cognitive impairment in addition to ASD-like behaviors. Neurobiol. Dis. 83, 67-74. doi: 10.1016/j.nbd.2015.08.016

Itakura, E., Kishi, C., Inoue, K., and Mizushima, N. (2008). Beclin 1 forms two distinct phosphatidylinositol 3-kinase complexes with mammalian Atg14 and UVRAG. Mol. Biol. Cell 19, 5360-5372. doi: 10.1091/mbc.E08-01-0080

Jentink, J., Loane, M. A., Dolk, H., Barisic, I., Garne, E., Morris, J. K., et al. (2010). Valproic acid monotherapy in pregnancy and major congenital malformations. N. Engl. J. Med. 362, 2185-2193. doi: 10.1056/NEJMoa0907328

Jung, C. H., Jun, C. B., Ro, S.-H., Kim, Y.-M., Otto, N. M., Cao, J., et al. (2009). ULK-Atg13-FIP200 complexes mediate mTOR signaling to the autophagy machinery. Mol. Biol. Cell 20, 1992-2003. doi: 10.1091/mbc.E08-12-1249

Kabeya, Y., Mizushima, N., Ueno, T., Yamamoto, A., Kirisako, T., Noda, T., et al. (2000). LC3, a mammalian homologue of yeast Apg8p, is localized in autophagosome membranes after processing. EMBO J. 19, 5720-5728. doi: 10.1093/emboj/19.21.5720

Kaushik, S., Rodriguez-Navarro, J. A., Arias, E., Kiffin, R., Sahu, S., Schwartz, G. J., et al. (2011). Autophagy in hypothalamic AgRP neurons regulates food intake and energy balance. Cell Metab. 14, 173-183. doi: 10.1016/j.cmet.2011.06.008

Kim, H. J., Cho, M. H., Shim, W. H., Kim, J. K., Jeon, E. Y., Kim, D. H., et al. (2017). Deficient autophagy in microglia impairs synaptic pruning and causes social behavioral defects. Mol. Psychiatry 22, 1576-1584. doi: 10.1038/mp.2016.103

Kim, J., Kundu, M., Viollet, B., and Guan, K.-L. (2011). AMPK and mTOR regulate autophagy through direct phosphorylation of Ulk1. Nat. Cell Biol. 13, 132-141. doi: $10.1038 /$ ncb2152

Klionsky, D. J., Abdelmohsen, K., Abe, A., Abedin, M. J., Abeliovich, H., Acevedo Arozena, A., et al. (2016). Guidelines for the use and interpretation of assays for monitoring autophagy (3rd edition). Autophagy 12, 1-222. doi: 10.1080/ 15548627.2015.1100356

Komatsu, M., Waguri, S., Chiba, T., Murata, S., Iwata, J., Tanida, I., et al. (2006). Loss of autophagy in the central nervous system causes neurodegeneration in mice. Nature 441, 880-884. doi: 10.1038/nature04723

Kuo, H.-Y., and Liu, F.-C. (2017). Valproic acid induces aberrant development of striatal compartments and corticostriatal pathways in a mouse model of autism spectrum disorder. FASEB J. 31, 4458-4471. doi: 10.1096/fj.201700054R

Kwon, C.-H., Luikart, B. W., Powell, C. M., Zhou, J., Matheny, S. A., Zhang, W., et al. (2006). Pten regulates neuronal arborization and social interaction in mice. Neuron 50, 377-388. doi: 10.1016/j.neuron.2006.03.023

Langen, M., Durston, S., Staal, W. G., Palmen, S. J. M. C., and van Engeland, H. (2007). Caudate nucleus is enlarged in high-functioning medication-naive subjects with autism. Biol. Psychiatry 62, 262-266. doi: 10.1016/j.biopsych.2006. 09.040

Langen, M., Schnack, H. G., Nederveen, H., Bos, D., Lahuis, B. E., de Jonge, M. V., et al. (2009). Changes in the developmental trajectories of striatum in autism. Biol. Psychiatry 66, 327-333. doi: 10.1016/j.biopsych.2009.03.017

Lauber, E., Filice, F., and Schwaller, B. (2016). Prenatal valproate exposure differentially affects parvalbumin-expressing neurons and related circuits in the cortex and striatum of mice. Front. Mol. Neurosci. 9:150. doi: 10.3389/fnmol. 2016.00150
Lee, K.-M., Hwang, S.-K., and Lee, J.-A. (2013). Neuronal autophagy and neurodevelopmental disorders. Exp. Neurobiol. 22, 133-142. doi: 10.5607/en. 2013.22.3.133

Li, L., Wang, Z. V., Hill, J. A., and Lin, F. (2014). New autophagy reporter mice reveal dynamics of proximal tubular autophagy. J. Am. Soc. Nephrol. 25, 305-315. doi: 10.1681/ASN.2013040374

Lieberman, O. J., Frier, M. D., McGuirt, A. F., Griffey, C. J., Rafikian, E., Yang, M., et al. (2020). Cell-type-specific regulation of neuronal intrinsic excitability by macroautophagy. eLife 9:e50843. doi: 10.7554/eLife.50843

Lieberman, O. J., McGuirt, A. F., Mosharov, E. V., Pigulevskiy, I., Hobson, B. D., Choi, S., et al. (2018). Dopamine triggers the maturation of striatal spiny projection neuron excitability during a critical period. Neuron 99, 540.e4554.e4. doi: 10.1016/j.neuron.2018.06.044

Lieberman, O. J., McGuirt, A. F., Tang, G., and Sulzer, D. (2019a). Roles for neuronal and glial autophagy in synaptic pruning during development. Neurobiol. Dis. 122, 49-63. doi: 10.1016/j.nbd.2018.04.017

Lieberman, O. J., Pigulevskiy, I., Post, M. R., Sulzer, D., and Santini, E. (2019b). mTOR suppresses macroautophagy during postnatal development of the striatum. bioRxiv [Preprint]. doi: 10.1101/536680

Maday, S., and Holzbaur, E. L. F. (2016). Compartment-Specific Regulation of Autophagy in Primary Neurons. J. Neurosci. 36, 5933-5945. doi: 10.1523/ JNEUROSCI.4401-15.2016

Magnuson, B., Ekim, B., and Fingar, D. C. (2012). Regulation and function of ribosomal protein $\mathrm{S} 6$ kinase (S6K) within mTOR signalling networks. Biochem. J. 441, 1-21. doi: 10.1042/BJ20110892

McMahon, J., Huang, X., Yang, J., Komatsu, M., Yue, Z., Qian, J., et al. (2012). Impaired autophagy in neurons after disinhibition of mammalian target of rapamycin and its contribution to epileptogenesis. J. Neurosci. 32, 15704-15714. doi: 10.1523/JNEUROSCI.2392-12.2012

Meador, K. J., Baker, G. A., Browning, N., Cohen, M. J., Bromley, R. L., ClaytonSmith, J., et al. (2013). Fetal antiepileptic drug exposure and cognitive outcomes at age 6 years (NEAD study): a prospective observational study. Lancet Neurol. 12, 244-252. doi: 10.1016/S1474-4422(12)70323-X

Mizushima, N., Yamamoto, A., Matsui, M., Yoshimori, T., and Ohsumi, Y. (2004). In vivo analysis of autophagy in response to nutrient starvation using transgenic mice expressing a fluorescent autophagosome marker. Mol. Biol. Cell 15, 11011111. doi: 10.1091/mbc.e03-09-0704

Moy, S. S., Nadler, J. J., Poe, M. D., Nonneman, R. J., Young, N. B., Koller, B. H., et al. (2008). Development of a mouse test for repetitive, restricted behaviors: relevance to autism. Behav. Brain Res. 188, 178-194. doi: 10.1016/j.bbr.2007.10. 029

Nicolini, C., and Fahnestock, M. (2018). The valproic acid-induced rodent model of autism. Exp. Neurol. 299, 217-227. doi: 10.1016/j.expneurol.2017.04.017

Nikoletopoulou, V., Sidiropoulou, K., Kallergi, E., Dalezios, Y., and Tavernarakis, N. (2017). Modulation of autophagy by BDNF underlies synaptic plasticity. Cell Metab. 26, 230.e5-242.e5. doi: 10.1016/j.cmet.2017.06.005

Ohsumi, Y. (2014). Historical landmarks of autophagy research. Cell Res. 24, 9-23. doi: $10.1038 /$ cr.2013.169

Peça, J., Feliciano, C., Ting, J. T., Wang, W., Wells, M. F., Venkatraman, T. N., et al. (2011). Shank3 mutant mice display autistic-like behaviours and striatal dysfunction. Nature 472, 437-442. doi: 10.1038/nature09965

Peixoto, R. T., Wang, W., Croney, D. M., Kozorovitskiy, Y., and Sabatini, B. L. (2016). Early hyperactivity and precocious maturation of corticostriatal circuits in Shank3B(-/-) mice. Nat. Neurosci. 19, 716-724. doi: 10.1038/nn. 4260

Peñagarikano, O., Abrahams, B. S., Herman, E. I., Winden, K. D., Gdalyahu, A., Dong, H., et al. (2011). Absence of CNTNAP2 leads to epilepsy, neuronal migration abnormalities, and core autism-related deficits. Cell 147, 235-246. doi: 10.1016/j.cell.2011.08.040

Plotkin, J. L., Wu, N., Chesselet, M.-F., and Levine, M. S. (2005). Functional and molecular development of striatal fast-spiking GABAergic interneurons and their cortical inputs. Eur. J. Neurosci. 22, 1097-1108. doi: 10.1111/j.1460-9568. 2005.04303.x

Poultney, C. S., Goldberg, A. P., Drapeau, E., Kou, Y., Harony-Nicolas, H., Kajiwara, Y., et al. (2013). Identification of small exonic CNV from wholeexome sequence data and application to autism spectrum disorder. Am. J. Hum. Genet. 93, 607-619. doi: 10.1016/j.ajhg.2013.09.001 
Qin, L., Dai, X., and Yin, Y. (2016). Valproic acid exposure sequentially activates Wnt and mTOR pathways in rats. Mol. Cell. Neurosci. 75, 27-35. doi: 10.1016/j. mcn.2016.06.004

Redmann, M., Benavides, G. A., Berryhill, T. F., Wani, W. Y., Ouyang, X., Johnson, M. S., et al. (2017). Inhibition of autophagy with bafilomycin and chloroquine decreases mitochondrial quality and bioenergetic function in primary neurons. Redox Biol. 11, 73-81. doi: 10.1016/j.redox.2016.11.004

Ronan, B., Flamand, O., Vescovi, L., Dureuil, C., Durand, L., Fassy, F., et al. (2014). A highly potent and selective Vps34 inhibitor alters vesicle trafficking and autophagy. Nat. Chem. Biol. 10, 1013-1019. doi: 10.1038/nchembio.1681

Roullet, F. I., Lai, J. K. Y., and Foster, J. A. (2013). In utero exposure to valproic acid and autism-a current review of clinical and animal studies. Neurotoxicol. Teratol. 36, 47-56. doi: 10.1016/j.ntt.2013.01.004

Rowland, A. M., Richmond, J. E., Olsen, J. G., Hall, D. H., and Bamber, B. A. (2006). Presynaptic terminals independently regulate synaptic clustering and autophagy of GABAA receptors in Caenorhabditis elegans. J. Neurosci. 26, 1711-1720. doi: 10.1523/JNEUROSCI.2279-05.2006

Russell, R. C., Tian, Y., Yuan, H., Park, H. W., Chang, Y.-Y., Kim, J., et al. (2013). ULK1 induces autophagy by phosphorylating Beclin-1 and activating VPS34 lipid kinase. Nat. Cell Biol. 15, 741-750. doi: 10.1038/ncb2757

Santini, E., Heiman, M., Greengard, P., Valjent, E., and Fisone, G. (2009). Inhibition of mTOR signaling in Parkinson's disease prevents L-DOPA-induced dyskinesia. Sci. Signal. 2:ra36. doi: 10.1126/scisignal.2000308

Santini, E., Huynh, T. N., MacAskill, A. F., Carter, A. G., Pierre, P., Ruggero, D., et al. (2013). Exaggerated translation causes synaptic and behavioural aberrations associated with autism. Nature 493, 411-415. doi: 10.1038/ nature 11782

Santini, E., Valjent, E., Usiello, A., Carta, M., Borgkvist, A., Girault, J.-A., et al. (2007). Critical involvement of cAMP/DARPP-32 and extracellular signalregulated protein kinase signaling in L-DOPA-induced dyskinesia. J. Neurosci. 27, 6995-7005. doi: 10.1523/JNEUROSCI.0852-07.2007

Sears, L. L., Vest, C., Mohamed, S., Bailey, J., Ranson, B. J., and Piven, J. (1999). An MRI study of the basal ganglia in autism. Prog. Neuropsychopharmacol. Biol. Psychiatry 23, 613-624. doi: 10.1016/S0278-5846(99)00020-22

Shafritz, K. M., Dichter, G. S., Baranek, G. T., and Belger, A. (2008). The neural circuitry mediating shifts in behavioral response and cognitive set in autism. Biol. Psychiatry 63, 974-980. doi: 10.1016/j.biopsych.2007.06.028

Shehata, M., Matsumura, H., Okubo-Suzuki, R., Ohkawa, N., and Inokuchi, K. (2012). Neuronal stimulation induces autophagy in hippocampal neurons that is involved in AMPA receptor degradation after chemical long-term depression. J. Neurosci. 32, 10413-10422. doi: 10.1523/JNEUROSCI.4533-11.2012

Shen, W., and Ganetzky, B. (2009). Autophagy promotes synapse development in Drosophila. J. Cell Biol. 187, 71-79. doi: 10.1083/jcb.200907109

Shmelkov, S. V., Hormigo, A., Jing, D., Proenca, C. C., Bath, K. G., Milde, T., et al. (2010). Slitrk5 deficiency impairs corticostriatal circuitry and leads to obsessivecompulsive-like behaviors in mice. Nat. Med. 16, 598-602. doi: 10.1038/nm. 2125

Shpilka, T., Weidberg, H., Pietrokovski, S., and Elazar, Z. (2011). Atg8: an autophagy-related ubiquitin-like protein family. Genome Biol. 12:226. doi: 10 . 1186/gb-2011-12-7-226

Silverman, J. L., Smith, D. G., Rizzo, S. J. S., Karras, M. N., Turner, S. M., Tolu, S. S., et al. (2012). Negative allosteric modulation of the mGluR5 receptor reduces repetitive behaviors and rescues social deficits in mouse models of autism. Sci. Transl. Med. 4:131ra51. doi: 10.1126/scitranslmed.3003501

Song, D. D., and Harlan, R. E. (1994). Genesis and migration patterns of neurons forming the patch and matrix compartments of the rat striatum. Brain Res. Dev. Brain Res. 83, 233-245. doi: 10.1016/0165-3806(94)00144-148

Stavoe, A. K. H., Hill, S. E., Hall, D. H., and Colón-Ramos, D. A. (2016). KIF1A/UNC-104 transports atg-9 to regulate neurodevelopment and autophagy at synapses. Dev. Cell 38, 171-185. doi: 10.1016/j.devcel.2016.06.012

Sutton, L. P., and Caron, M. G. (2015). Essential role of D1R in the regulation of mTOR complex1 signaling induced by cocaine. Neuropharmacology 99, 610-619. doi: 10.1016/j.neuropharm.2015.08.024

Tang, G., Gudsnuk, K., Kuo, S.-H., Cotrina, M. L., Rosoklija, G., Sosunov, A., et al. (2014). Loss of mTOR-dependent macroautophagy causes autistic-like synaptic pruning deficits. Neuron 83, 1131-1143. doi: 10.1016/j.neuron.2014. 07.040
Tanida, I., Minematsu-Ikeguchi, N., Ueno, T., and Kominami, E. (2005). Lysosomal turnover, but not a cellular level, of endogenous LC3 is a marker for autophagy. Autophagy 1, 84-91. doi: 10.4161/auto.1.2.1697

Tepper, J. M., Sharpe, N. A., Koós, T. Z., and Trent, F. (1998). Postnatal development of the rat neostriatum: electrophysiological, light- and electronmicroscopic studies. Dev. Neurosci. 20, 125-145. doi: 10.1159/000017308

Thomas, A., Burant, A., Bui, N., Graham, D., Yuva-Paylor, L. A., and Paylor, R. (2009). Marble burying reflects a repetitive and perseverative behavior more than novelty-induced anxiety. Psychopharmacology 204, 361-373. doi: 10.1007/ s00213-009-1466-y

Thomas, A. M., Bui, N., Perkins, J. R., Yuva-Paylor, L. A., and Paylor, R. (2012). Group I metabotropic glutamate receptor antagonists alter select behaviors in a mouse model for fragile X syndrome. Psychopharmacology 219, 47-58. doi: 10.1007/s00213-011-2375-2374

Thoreen, C. C., Kang, S. A., Chang, J. W., Liu, Q., Zhang, J., Gao, Y., et al. (2009). An ATP-competitive mammalian target of rapamycin inhibitor reveals rapamycin-resistant functions of mTORC1. J. Biol. Chem. 284, 8023-8032. doi: 10.1074/jbc.M900301200

Tsai, P. T., Hull, C., Chu, Y., Greene-Colozzi, E., Sadowski, A. R., Leech, J. M., et al. (2012). Autistic-like behaviour and cerebellar dysfunction in Purkinje cell Tsc1 mutant mice. Nature 488, 647-651. doi: 10.1038/nature1 1310

Tsai, P. T., Rudolph, S., Guo, C., Ellegood, J., Gibson, J. M., Schaeffer, S. M., et al. (2018). Sensitive periods for cerebellar-mediated autistic-like behaviors. Cell Rep. 25, 357.e4-367.e4. doi: 10.1016/j.celrep.2018.09.039

Tsvetkov, A. S., Miller, J., Arrasate, M., Wong, J. S., Pleiss, M. A., and Finkbeiner, S. (2010). A small-molecule scaffold induces autophagy in primary neurons and protects against toxicity in a Huntington disease model. Proc. Natl. Acad. Sci. U.S.A. 107, 16982-16987. doi: 10.1073/pnas.1004498107

Voorn, P., Kalsbeek, A., Jorritsma-Byham, B., and Groenewegen, H. J. (1988). The pre- and postnatal development of the dopaminergic cell groups in the ventral mesencephalon and the dopaminergic innervation of the striatum of the rat. Neuroscience 25, 857-887. doi: 10.1016/0306-4522(88)9004190043

Wang, Q. J., Ding, Y., Kohtz, D. S., Mizushima, N., Cristea, I. M., Rout, M. P., et al. (2006). Induction of autophagy in axonal dystrophy and degeneration. J. Neurosci. 26, 8057-8068. doi: 10.1523/JNEUROSCI.2261-06.2006

Wang, R., Tan, J., Guo, J., Zheng, Y., Han, Q., So, K.-F., et al. (2018). Aberrant development and synaptic transmission of cerebellar cortex in a VPA induced mouse autism model. Front. Cell Neurosci. 12:500. doi: 10.3389/fncel.2018. 00500

Werler, M. M., Ahrens, K. A., Bosco, J. L. F., Mitchell, A. A., Anderka, M. T., Gilboa, S. M., et al. (2011). Use of antiepileptic medications in pregnancy in relation to risks of birth defects. Ann. Epidemiol. 21, 842-850. doi: 10.1016/j.annepidem. 2011.08.002

Wu, H., Zhang, Q., Gao, J., Sun, C., Wang, J., Xia, W., et al. (2018). Modulation of sphingosine 1-phosphate (S1P) attenuates spatial learning and memory impairments in the valproic acid rat model of autism. Psychopharmacology 235, 873-886. doi: 10.1007/s00213-017-4805-4804

Yamamoto, A., Cremona, M. L., and Rothman, J. E. (2006). Autophagy-mediated clearance of huntingtin aggregates triggered by the insulin-signaling pathway. J. Cell Biol. 172, 719-731. doi: 10.1083/jcb.200510065

Yamamoto, A., and Simonsen, A. (2011). The elimination of accumulated and aggregated proteins: a role for aggrephagy in neurodegeneration. Neurobiol. Dis. 43, 17-28. doi: 10.1016/j.nbd.2010.08.015

Yamamoto, A., Tagawa, Y., Yoshimori, T., Moriyama, Y., Masaki, R., and Tashiro, Y. (1998). Bafilomycin A1 prevents maturation of autophagic vacuoles by inhibiting fusion between autophagosomes and lysosomes in rat hepatoma cell line, H-4-II-E cells. Cell Struct. Funct. 23, 33-42. doi: 10.1247/csf.23.33

Yamamoto, A., and Yue, Z. (2014). Autophagy and its normal and pathogenic states in the brain. Annu. Rev. Neurosci. 37, 55-78. doi: 10.1146/annurev-neuro071013-14149

Yan, J., Porch, M. W., Court-Vazquez, B., Bennett, M. V. L., and Zukin, R. S. (2018). Activation of autophagy rescues synaptic and cognitive deficits in fragile X mice. Proc. Natl. Acad. Sci. U.S.A. 115, E9707-E9716. doi: 10.1073/pnas.1808247115

Yang, D.-S., Stavrides, P., Mohan, P. S., Kaushik, S., Kumar, A., Ohno, M., et al. (2011). Reversal of autophagy dysfunction in the TgCRND8 mouse model of 
Alzheimer's disease ameliorates amyloid pathologies and memory deficits. Brain 134, 258-277. doi: 10.1093/brain/awq341

Yin, H. H., Davis, M. I., Ronesi, J. A., and Lovinger, D. M. (2006). The role of protein synthesis in striatal long-term depression. J. Neurosci. 26, 11811-11820. doi: 10.1523/JNEUROSCI.3196-06.2006

Zhang, J., Zhang, J.-X., and Zhang, Q.-L. (2016). PI3K/AKT/mTOR-mediated autophagy in the development of autism spectrum disorder. Brain Res. Bull. 125, 152-158. doi: 10.1016/j.brainresbull.2016.06.007

Zhang, Y., Xiang, Z., Jia, Y., He, X., Wang, L., and Cui, W. (2019). The Notch signaling pathway inhibitor Dapt alleviates autism-like behavior, autophagy and dendritic spine density abnormalities in a valproic acid-induced animal model of autism. Prog. Neuropsychopharmacol. Biol. Psychiatry 94:109644. doi: 10.1016/j.pnpbp.2019.109644

Zhou, J., Blundell, J., Ogawa, S., Kwon, C.-H., Zhang, W., Sinton, C., et al. (2009). Pharmacological inhibition of mTORC1 suppresses anatomical, cellular, and behavioral abnormalities in neural-specific Pten knockout mice. J. Neurosci. 29, 1773-1783. doi: 10.1523/JNEUROSCI.5685-08. 2009

Conflict of Interest: The authors declare that the research was conducted in the absence of any commercial or financial relationships that could be construed as a potential conflict of interest.

Copyright (ㄷ 2020 Lieberman, Cartocci, Pigulevskiy, Molinari, Carbonell, Broseta, Post, Sulzer, Borgkvist and Santini. This is an open-access article distributed under the terms of the Creative Commons Attribution License (CC BY). The use, distribution or reproduction in other forums is permitted, provided the original author(s) and the copyright owner(s) are credited and that the original publication in this journal is cited, in accordance with accepted academic practice. No use, distribution or reproduction is permitted which does not comply with these terms. 